\title{
Quia non ascendit suma: la riqueza del clero de la ciudad de Zaragoza durante la Baja Edad Media (1272-1456)*
}

\author{
Esther Tello Hernández ${ }^{1}$ \\ EEHAR-Roma/Universidad de Valencia \\ Esther.Tello@uv.es
}

RESUMEN: El objetivo de este artículo es estudiar la riqueza y la desigualdad socioeconómica del clero zaragozano a través de las fuentes fiscales durante la Baja Edad Media. Mediante el análisis de los libros de décimas pontificias conservados en el Archivo de la Corona de Aragón y en el Archivo Apostólico Vaticano es posible documentar la tasa contributiva de los clérigos aragoneses, en general, y de los zaragozanos, en particular. En concreto, a través de un estudio cronológico amplio, se puede definir la estructura y la jerarquía de la Iglesia zaragozana, comprobar cómo evolucionó la

* El presente trabajo se ha elaborado en el marco de los grupos de investigación «Desigualdad económica y movilidad social en la Europa Mediterránea, siglos XIII-XVI» (ref. Prometeo2019/072) y «Renda feudal i fiscalidad a la Catalunya Baix-Medieval» (ref. 2017SGR-1068), y de los proyectos de investigación del Ministerio de Ciencia, Innovación y Universidades «¿Crecimiento sin desarrollo? Distribución de la riqueza, movilidad social y acción política en la Europa Mediterránea (siglos XIII-XV)» (ref. PGC2018-099275) de la Universitat de València y «La desigualdad económica en las ciudades catalanas y mallorquinas durante la Baja Edad Media» (ref. PGC2018-100979-B-C22) de la Institución Milá y Fontanals de Investigación en Humanidades (IMF-CSIC. Barcelona). Asimismo, buena parte de este trabajo se comenzó a fraguar durante mi etapa como investigadora postdoctoral en la Escuela Española de Historia y Arqueología en Roma.

La presente publicación forma parte de un proyecto de mayor calado que tiene como propósito estudiar la evolución de las tasas beneficiales en los obispados de la Corona de Aragón durante los siglos XIV y XV. Fruto de ello son las obras de TELLO, 2019b: 103-120 y de MORELLÓ, en prensa.

Abreviaturas de Archivos: Archivo de la Corona de Aragón, Barcelona, ACA, sección Real Patrimonio, RP, sección Real Cancillería, C; Archivo Apostólico Vaticano, Ciudad del Vaticano, AAV, serie Colectoría, Coll.

${ }^{1}$ ORCID iD: https://orcid.org/0000-0002-5985-3791.

Copyright: (C) 2021 CSIC. Este es un artículo de acceso abierto distribuido bajo los términos de una licencia de uso y distribución Creative Commons Reconocimiento 4.0 Internacional (CC-BY 4.0) 
riqueza de los eclesiásticos y cómo afectaron a este grupo heterogéneo las diferentes coyunturas económicas que se produjeron en la Corona de Aragón a finales de la época medieval.

Palabras Clave: fiscalidad; Corona de Aragón; Zaragoza; geografía fiscal; subsidios eclesiásticos; Alfonso V.

Quia non ascendit suma: the wealth of the clergy in the city of Saragossa in the Late Middle Ages (1272-1456)

ABSTRACT: The aim of this article is to study the socioeconomic wealth and inequality of the Saragossan clergy during the Late Middle Ages through tax sources. An analysis of the pontifical tithe registers preserved in the Archive of the Crown of Aragon and the Vatican Apostolic Archive makes it possible to document the tax contribution of the Aragonese clergy in general, and of Saragossa's ecclesiastics in particular. Specifically, by means of a broad chronological study, we can define the structure and hierarchy of the Church of Saragossa, how the wealth of the ecclesiastics evolved and how the different economic circumstances that existed under the Crown of Aragon during the Late Middle Ages affected this heterogeneous group.

KEY WORDS: taxation; Crown of Aragon; Saragossa; fiscal geography; ecclesiastical subsidies; Alfonso V.

CÓMO CITAR ESTE ARTÍCULO/CITATION: Tello Hernández, Esther, «Quia non ascendit suma: la riqueza del clero de la ciudad de Zaragoza durante la Baja Edad Media (12721456)», Hispania, 81/267 (Madrid, 2021): 11-43. https://doi.org/10.3989/hispania.2021.001.

\section{INTRODUCCIÓN: CUANTIFICAR LA RIQUEZA DEL CLERO}

Durante el reinado de Alfonso el Magnánimo (1416-1458), la maquinaria hacendística de la Corona de Aragón funcionaba a pleno rendimiento. Una de las prioridades era la búsqueda de ingresos adicionales que permitieran al monarca Trastámara hacer frente a sus campañas bélicas, tanto en Castilla (1425, 1429-1430) como, sobre todo, en Italia: las campañas del sur (1416-1423), la guerra de Nápoles (1435-1443) y las operaciones en la Italia central (1443$1448)^{2}$. A la hora de solicitar el apoyo económico de la Iglesia, el Magnánimo buscó obtener el difícil beneplácito de los pontífices, así como el soporte de las principales dignidades eclesiásticas diocesanas. A grandes rasgos, las vías habituales de contribución eclesiástica fueron los donativos en Cortes, los sub-

2 ABULAFIA, 2009: 97-112; 1997. SOLDANI, 2007: 266-324. ÁLVAREZ PALENZUELA, 1996: 65-89. RYDER, 1987.

Hispania, 2021, vol. LXXXI, n. ${ }^{\circ}$ 267, enero-abril, págs. 11-43, ISSN: 0018-2141, e-ISSN: 1988-8368 
sidios y ayudas particulares $\mathrm{y}$, en menor medida durante estos años, la cesión de impuestos pontificios como la décima ${ }^{3}$.

A lo largo del reinado del Alfonso V se recaudaron seis subsidios eclesiásticos en los territorios peninsulares. Entre todos ellos, destaca el promulgado en 1443 por el papa Eugenio IV con el fin de financiar la guerra de le Marche. Este conflicto tuvo lugar poco después de la conquista de Nápoles y afectó, fundamentalmente, a los dominios del papado en la Italia central. Para dar soporte al papado y asegurar la frontera en los Abruzos, las tropas del monarca combatieron al conde Francesco Sforza en la Marca de Ancona. Y, con el propósito de llevar a cabo tal empresa, se aprobó un subsidio de 200.000 florines, de los cuales 140.000 debían ser aportados por los territorios occidentales de la Corona de Aragón. Como era costumbre, los eclesiásticos debían costearlo de forma proporcional a sus rentas patrimoniales. Para ello, su contribución estaba basada en la tasa decimal, la cual suponía - a grandes rasgos - el 10\% de los ingresos netos anuales de que disponía cada beneficio eclesiástico ${ }^{4}$.

Lo insólito de este episodio es que, a raíz del nuevo subsidio, se procedió a actualizar las tasas decimales que, desde hacía décadas, estaban prácticamente fosilizadas. Cada vez que se ponía en marcha una décima pontificia o un subsidio eclesiástico, se tomaban como referencia los libros contables de recaudaciones anteriores, con unos datos que no siempre estaban actualizados. Esto tuvo dos consecuencias fundamentales: por una parte, esta descontextualización suponía que la riqueza real del beneficio y, por ende, la del eclesiástico que lo ostentaba, no se correspondía con la realidad contemporánea ${ }^{5}$. Por otra parte, muchos de los beneficios, sobre todo los de creación más reciente, escapaban del control regio al no documentase de manera sistemática en los libros de tasas. En este contexto, y a instancias del papa Eugenio IV, se preparó una «manifiestaciò de les rendes e valors de les prelatures, dignitats e beneficis» con el fin de poner al día la tasa contributiva ${ }^{6}$. La iniciativa se llevó a cabo a

${ }^{3}$ Para contextualizar la contribución de la Iglesia a las demandas de la monarquía durante el siglo XV y cómo la guerra se convirtió en el principal motor del desarrollo del estado fiscal, véanse: KÜCHLER, 1997: 269-237. SÁNCHEZ, FURIÓ Y SESMA 2008: 99-130. CAROCCI y COLLAVINI, 2014: 125-158. MORELLÓ, 2017: 656-658.

${ }^{4}$ Sobre este subsidio particular, remito a KÜCHLER, 1997: 218-219. MORELLÓ, 2015: 289-297.

5 Según la mayoría de los autores, las tasas decimales estarían fosilizadas desde finales del siglo XIII o comienzos del XIV. Por esta razón, tal como indican J. Favier o J. Morerod, la taxatio ad decimam no permite calcular el valor real y actualizado de un beneficio eclesiástico durante un periodo prolongado (FAVIER, 1964: 125. MOREROD, 1990: 338. LE ROUX, 2015: 59). Para la Corona de Aragón, tal como señala J. Morelló, parece ser que fue también a finales del siglo XIII o comienzos del XIV cuando se fijaron estas tasas que serían aplicadas sistemáticamente en las décadas posteriores sin apenas sufrir variaciones hasta comienzos del siglo XV (MORELLÓ, 2015: 290).

${ }^{6}$ KUCHLER, 1997: 230 (citado en ACA, Real Cancillería, reg. 2931, f. 103). 
través de un complejo proceso de averiguaciones de rentas que ha sido estudiado en profundidad para el obispado de Barcelona por J. Morelló 7 . A grandes rasgos, una administración mixta creada ex professo se encargó de anotar los valores de las rentas de todos los beneficiados (desde los obispos hasta los rectores y demás beneficiados) conforme a los ingresos y gastos de su patrimonio, tomando como referencia la situación de los años anteriores y añadiendo las declaraciones coetáneas de los religiosos 8 .

En el presente artículo, a través del estudio de estos libros de tasas, se pretende llevar a cabo una estimación de la riqueza del clero de la ciudad de Zaragoza durante la Baja Edad Media y de las principales dignidades eclesiásticas urbanas. Para ello, tomo como referencia varios libros contables que se elaboraron durante los siglos XIV y XV, si bien se hace especial mención en el punto de inflexión que supuso la revisión de tasas de mediados del siglo XV. Pese a que no se puede determinar con seguridad si las tasas contributivas que aparecían en los libros de tasas equivalían exactamente a un 10\% del rendimiento real, el cambio y la evolución de estas tasas sí nos dan una idea bastante aproximada sobre la situación socioeconómica del clero y, sobre todo, su potencial económico. Finalmente, un estudio de estas características nos acerca, además, a conocer mejor la estructura y organización de la clerecía del obispado y, más en concreto, de la red parroquial de la ciudad de Zaragoza durante el periodo bajomedieval ${ }^{9}$.

${ }^{7}$ Como resultado de este proceso, se llevaron a cabo en toda la Corona de Aragón los llamados registros de veros valores que hoy se conservan en el Archivo de la Corona de Aragón y en multitud de archivos eclesiásticos. Son, pues, una fuente excepcional para el estudio del clero de mediados del siglo XV. Y es que, si bien muchas de estas sirvieron de base a la hora de calcular cualquier otro tipo de contribución del clero, también fueron de referencia para llevar a cabo las revalorizaciones posteriores. Para el caso ya estudiado de Barcelona, véase MORELLÓ, 2015: 289-322, en especial, 294-297. El registro correspondiente a los veros valores del obispado de Zaragoza se encuentra en: ACA, RP, reg. 1917.

${ }^{8}$ Unos años más tarde, en 1448, Alfonso V publicó un edicto fundamental que también marcó un antes y un después en las relaciones Iglesia-Estado. A grandes rasgos, el monarca pretendía preparar un inventario del patrimonio general de los eclesiásticos de la Corona y rendir así cuentas de sus bienes inmuebles, rentas patrimoniales e ingresos benefíciales (KÜCHLER, 1997: 269-326. MORELLÓ, 2017: 657-658). En Castilla fue en torno a 1457, en el contexto de la cruzada contra los turcos otomanos y los subsidios para la guerra contra Granada, cuando también se llevaron a cabo averiguaciones de rentas eclesiásticas que se prolongaron durante el siglo siguiente (VILLARROEL, 2011: 316 y ss. PERRONE, 2008. NIETO SORIA, 1993: 113-131).

9 En este contexto, no podemos olvidar cómo en los últimos años han proliferado investigaciones que tienen como objeto de estudio la desigualdad en la riqueza de las sociedades preindustriales (ALFANI-TULLIO, 2019. STIGLITZ, 2012. PIKETTY, 2008). Del mismo modo, en la Corona de Aragón esta relación entre la desigualdad y la riqueza va pareja a una reflexión historiográfica sobre lo que supuso, en realidad, la rebatida crisis bajomedieval (CATEURATUDELA, 2019. FURIÓ, 2010: 13-16). En última instancia, este estudio también se inscribe en 
Sin embargo, antes de entrar de lleno en estas cuestiones, es necesario definir brevemente en qué consistía la política beneficial y cómo los libros de tasas son una fuente fiscal de primer orden para realizar estudios sobre las rentas patrimoniales del clero. En segundo lugar, se presenta un análisis de caso sobre la situación socioeconómica de los eclesiásticos zaragozanos durante la Baja Edad Media, tomando como referencia cuatro de las principales valoraciones decimales realizadas durante el periodo $(1279,1354,1397$ y 1456). En este sentido, se analiza el patrimonio y evolución de las dignidades eclesiásticas de la ciudad, de las capellanías de las principales sedes religiosas, así como de los rectores y vicarios parroquiales. En último lugar, se realizan unas breves consideraciones finales recalcando el potencial de estas fuentes para el estudio de la desigualdad socioeconómica del clero.

LAS TASAS SOBRE LOS BENEFICIOS ECLESIÁSTICOS: DE LAS RATIONES DECIMARUM (1279) hasta la proclama de Alfonso el Magnánimo (1443)

Como ya se ha escrito en numerosas ocasiones, por beneficio eclesiástico se entiende un ente jurídico al frente del cual estaba un clérigo que tenía unas rentas asignadas que le permitían su sustento, así como el mantenimiento de la actividad religiosa. Estas rentas estaban en la base de numerosos impuestos pontificios, tales como la décima o el subsidio, o de otras peticiones regias. Gracias a la conservación de fuentes seriadas y a la homogeneidad de estas, puede realizarse un estudio de largo recorrido desde los orígenes del sistema beneficial hasta la segunda mitad del siglo $\mathrm{XV}^{10}$.

\section{La larga trayectoria de la fiscalidad beneficial: la décima pontificia}

El origen del sistema beneficial se remonta a los siglos XII y XIII y su difusión está estrechamente relacionada con la proliferación de los impuestos sobre la renta eclesiástica ${ }^{11}$. Uno de los tributos que mejor refleja la tasación beneficial a lo largo de este periodo fue la décima pontificia. La décima era un

\footnotetext{
las investigaciones que se están llevando a cabo en torno a la tradicionalmente llamada geografía fiscal (LADERO, 2014: 47, 50-51; 1991: 104-107). Además, durante los últimos años, la reorientación de esta cuestión ha permitido afrontar tal argumento desde un punto de vista económicosocial (SALAS, 2011. PEZZOLO, 2013. ORTEGO, 2012. TRIANO, 2018).

10 Véase como definición general de beneficio eclesiástico, entre otros muchos: LEVILLAIN, 1994: 410-411.

${ }^{11}$ Para una introducción a la evolución de los impuestos que gravaban la renta de los eclesiásticos en base a la tasa decimal desde los siglos XII-XIII, véase: MARDIÈRE-CHEVREAU, 2012: 23-28.
}

Hispania, 2021, vol. LXXXI, n. ${ }^{\circ}$ 267, enero-abril, págs. 11-43, ISSN: 0018-2141, e-ISSN: 1988-8368 https://doi.org/10.3989/hispania.2021.001 
impuesto promulgado por el papado y tenía como finalidad la defensa de Tierra Santa y servir a los intereses de la Santa Sede. Su base impositiva, fundamentada en la tasa decimal, ya había quedado definida en el IV Concilio de Letrán (1215-1216), si bien la exacción se generalizó a partir del II Concilio de Lyon (1274). Fue entonces cuando el papa Gregorio X promulgó una décima que debía ser percibida en todos los reinos del Occidente cristiano durante seis años $^{12}$. Gracias a ello, en el Archivo Vaticano se conservan numerosos libros de cuentas de la recaudación del impuesto referentes a la mayoría de las diócesis europeas que han sido editados casi en su totalidad ${ }^{13}$.

Estos registros nos muestran un incipiente sistema beneficial que aún estaba por expandirse unas décadas más tarde. En particular, este sistema se consolidó durante el papado de Aviñón (1309-1378), en paralelo al desarrollo de la propia fiscalidad papal. Como es sabido, con el establecimiento del papado en Aviñón se produjo una generalización de los impuestos pontificios orientados a nutrir las necesitadas arcas pontificias a través del principal órgano financiero de la hacienda papal, la Cámara Apostólica. Por ello, no es de extrañar que la décima se consolidase como el impuesto pontificio por excelencia ya que permitía al papado percibir numerario de todas las diócesis de la cristiandad a través de los colectores y subcolectores eclesiásticos. Por su parte, las monarquías cristianas, también con unos sistemas fiscales cada vez más afianzados, supieron aprovecharse de esta inercia y se erigieron, en buena medida, como receptoras de la totalidad o parte de la décima ${ }^{14}$.

Esta dinámica continuó así hasta comienzos del siglo XV, cuando se observa un punto de inflexión en el Concilio de Constanza (1414-1419). A partir de entonces, las décimas solo podían ser promulgadas desde el papado con carácter universal y debían servir al interés general del Occidente cristiano y no tanto al de los monarcas europeos ${ }^{15}$. Como resultado de ello, comenzó a proliferar el subsidio pontificio, una exacción que también debía promulgar el papa, pero que hasta el momento no había tenido un gran recorrido en la Corona de

12 Para una definición de décima pontificia, acúdase a los estudios clásicos de W. E. Lunt y J. Favier (LUNT, 1943. FAVIER, 1966). Para la Corona de Aragón remito a las obras de BERTRAN, 1990: 66-69; 1997: 291-293. SÁNCHEZ, 1995: 1280-1283. MORELLÓ, 2017: 651-656. TELLO, 2020: 91-122.

${ }_{13}$ En el caso de la Corona de Aragón, las Rationes decimarum del bienio 1279-1280 fueron transcritas y publicadas íntegramente por J. Rius Serra (RIUS, 1946). Asimismo, las Rationes decimarum de finales del siglo XIII también han sido publicadas y estudiadas en la mayor parte de territorios italianos y francés: BATTELLI, 1946. CAUSSE, 1988. RONZANI, 2012.

${ }_{14}$ Sobre este centralismo pontificio, acúdase a los estudios clásicos de PIOLA, 1990. MOLLAT-SAMARAN, 1905. LUNT, 1965, etc. Para Francia, por ejemplo, véase como referencia general las obras de CAUSSE, 1988: 148-163. LE ROUX, 2015: 55-80.

15 Para los cambios estructurales que se produjeron tras el concilio de Constanza en materia fiscal, véase: STUMP, 2009: 395-443.

Hispania, 2021, vol. LXXXI, n. ${ }^{\circ}$ 267, enero-abril, págs. 11-43, ISSN: 0018-2141, e-ISSN: 1988-8368 
Aragón ${ }^{16}$. Por lo que respecta a la tasación fiscal, las nuevas contribuciones continuaron estando basadas en las tasas decimales, aunque las cantidades solicitadas eran cada vez más elevadas. En concreto, al aprobarse un subsidio, la cuantía total de la ayuda se distribuía de manera proporcional entre las diferentes diócesis y los eclesiásticos eran tasados «per solidum et libram», según el porcentaje establecido ${ }^{17}$. Más tarde, durante la segunda mitad del siglo XV y, en especial, a partir del pontificado de Calixto III (1355-1358) volvieron a proliferar las décimas pontificias, eso sí, con un carácter universal (orientadas a la lucha contra los turcos y a recuperar Constantinopla) y no destinadas —en exclusiva- a las arcas de los príncipes cristianos ${ }^{18}$.

\section{La valoración decimal en la Corona de Aragón durante la baja Edad Media}

En la Corona de Aragón, en general, y en el obispado de Zaragoza, en particular, se puede testimoniar lo descrito anteriormente. La enfeudación de la isla de Cerdeña por parte del papado, a finales del siglo XIII, y la posterior conquista de la isla, en la década de 1320 , permite comprender mejor la escalada de presión fiscal y el interés existente por parte de la corona para llevar a cabo el complicado dominio efectivo de la isla durante las décadas siguientes ${ }^{19}$. De hecho, desde mediados del siglo XIV, la voluble situación de Cerdeña fue un asunto recurrente en las políticas de Pedro IV el Ceremonioso y del papado, razón por la cual el impuesto de la décima fue establecido, sin solución de continuidad, para la pacificación de la isla. De este modo, como ya se ha señalado en alguna ocasión, la décima se convirtió en un impuesto casi ordinario para la

${ }^{16}$ MORELLÓ, 2017: 656-657. KÜCHLER, 1997: 210-259. Para la Corona de Castilla, el peso que alcanzaron los subsidios eclesiásticos ha sido estudiado ampliamente, entre otros, por VILLARROEL, 2013: 319-344. MONTES, 2009: 649-664.

${ }_{17}$ Tal como explican J. Morelló o W. Küchler, la tendencia se situó al alza durante todo el periodo: de los 50.000 florines de Cámara solicitados en 1418, se pasó a los 100.000 florines del subsidio en 1433, a 140.000 florines en 1443 y a 185.000 florines en 1451 (KÜCHLER, 1997: 233-240. MORELLÓ, 2017: 655. BAUCELLS, 1984: 11-33).

18 MORELLÓ, 2017: 658-660. FORTEA, 2015: 473-508. KÜCHLER, 1997: 236-259. NAVARRO SORNI, 2009: 247-260, 2003.

${ }_{19}$ Como es sabido, tras el tratado de Anagni firmado entre el papa Bonifacio VIII y Jaime II de Aragón, Felipe IV de Francia y Carlos II de Anjou en 1295, Cerdeña y Córcega fueron cedidas a Jaime II como territorios vasallos de la Santa Sede (HINOJOSA, 2005: 177-181). Desde este momento, las relaciones entre Jaime II y la Santa Sede y, en particular, los asuntos de Cerdeña y el Mediterráneo fueron, pues, punto de encuentro y desencuentro entre los reyes aragoneses y el papado durante buena parte de la Baja Edad Media (PÉQUIGNOT, 2009: 141166. FÀBREGA, 1959: 461-475. BAYDAL, 2009: 57-154). Sobre la escalada de presión fiscal que se dio durante este periodo en lo relativo a Cerdeña, remito a los estudios de LAFUENTE, 2017: 113-146. SÁNCHEZ, 2005: 363-393. 
hacienda regia hasta la primera década del siglo $X V^{20}$. El hecho de transformarse en un recurso habitual para la monarquía y de asentarse sobre una base imponible fundamentada en la renta eclesiástica, permitió que incluso los soberanos aragoneses llegasen a prever aproximadamente lo que se recaudaría del impuesto $^{21}$. Sin embargo, el desconocimiento real del número de beneficios y la necesidad de saber las rentas efectivas de las que se nutrían los eclesiásticos, hizo que la corona también mostrase un creciente interés por clarificar estos datos. Tal como establece J. Morelló, no fue hasta comienzos del siglo XV cuando se realizaron pequeñas tentativas en la Corona de Aragón ${ }^{22}$. Pero, sobre todo, fue a raíz del subsidio eclesiástico de 1443, solicitado por Eugenio IV para financiar las acciones bélicas del Magnánimo en Italia, cuando se emprendió una importante tarea que consistió, tal como ya se ha indicado, en revalorar la tasación de los beneficios eclesiásticos.

\section{Las tasas decimales en el obispado de Zaragoza: la radiografía fiscal del clero zaragozano (1272-1456)}

Entre 1272 y 1456 estuvieron vigentes, al menos, veinte décimas pontificias que afectaron a la diócesis de Zaragoza. La mayoría de ellas tuvieron una duración bienal, si bien durante la segunda mitad del siglo XIV también proliferaron las anuales y trienales ${ }^{23}$. En particular, durante la segunda parte del reinado del Ceremonioso y hasta el inicio del Cisma (1349-1379), se recaudó el impuesto durante diecinueve años. Asimismo, tampoco debe sorprendernos que durante los reinados de Juan I (1387-1396) y Martín I (1396-1410) se promulgaron seis décimas que fueron recaudadas, sin solución de continuidad,

${ }^{20}$ Un hecho significativo es que prácticamente desde 1345 hasta 1409, salvo los años de la indiferencia del Ceremonioso durante los primeros años del Cisma de Occidente, la décima se recaudó en la Corona de Aragón casi cada año, y su producto fue destinado, total o parcialmente, a los monarcas aragoneses (SÁNCHEZ, 1995: 1277-1296. BERTRAN, 1997: 291-293. MORELLÓ, 2011a: 167-190. TELLO, 2020: 175-216. BERTRAN, 1997: 291-293).

${ }^{21}$ Por ejemplo, el 28 de abril de 1375, el monarca escribía una carta en la que preveía que el monto total de la recaudación de la décima pontificia recién promulgada ascendería a unos 330.000 sueldos barceloneses anuales en toda la Corona: ACA, Real Cancillería, reg. 1460, ff. 13v-14r (Lérida, 28/04/1375). La cantidad mencionada coincida, aproximadamente, con lo que se había recaudado en los años anteriores y con lo que se percibió en dicha colecta y en las sucesivas (TELLO, 2020; 2019a. MORELLÓ, 2011a. SÁNCHEZ, 1995).

${ }^{22}$ MORELLÓ, 2011a: 178. Por su parte, en Francia parece ser que ya hubo revisiones de las tasas en las décadas de 1360 y 1370 . En particular, B. Causse documenta varias bulas durante este periodo donde se establecieron importantes rebajas generales (CAUSSE, 1988: 323-329). Para Castilla, véase esta cuestión en LADERO, 1993: 203.

${ }^{23}$ Tan solo la décima de 1274 tuvo una duración sexenal y la de 1393 fue promulgada durante diez años.

Hispania, 2021, vol. LXXXI, n. ${ }^{\circ}$ 267, enero-abril, págs. 11-43, ISSN: 0018-2141, e-ISSN: 1988-8368

https://doi.org/10.3989/hispania.2021.001 
desde 1387 hasta $1407^{24}$. En cuanto al destino del impuesto, durante buena parte del periodo estudiado, la totalidad de la recaudación (o casi la totalidad) iba a parar a los monarcas aragoneses. Fue a partir del reinado de Juan I cuando sus ingresos se repartieron de manera habitual entre el rey (que percibía dos terceras partes del total) y el papa (quien se erigía beneficiario de la tercera parte restante) ${ }^{25}$. Esta transferencia de renta pontificia a la monarquía es la razón por la cual se han conservado multitud de libros de décimas en el Archivo Real. Al ser un impuesto cedido al monarca, los subcolectores eclesiásticos encargados de su percepción en cada obispado debían rendir cuentas de su gestión ante el maestre racional, principal oficial financiero de la corona y supervisor de las rentas regias ${ }^{26}$.

Para llevar a cabo este estudio, me he servido de cuatro libros de cuentas de décimas pontificias referentes al obispado de Zaragoza. En primer lugar, se ha tomado como referencia el libro contable de la última anualidad (12791280) de la recaudación de una décima sexenal, promulgada en el ya mencionado II Concilio de Lyon en 1274. En segundo lugar, se han sistematizado los datos de una anualidad de la décima bienal de 1355 que proclamó Inocencio VI. En tercer lugar, se ha hecho lo propio con otro registro de la décima trienal de 1397, ya en época del papa Benedicto XIII. Y, por último, se ha acudido a otro libro contable de la recaudación de la décima contra el Turco de 1456, establecida por Calixto III y que recoge las tasas actualizadas posteriormente al subsidio de $1443^{27}$.

A grandes rasgos, cada uno de estos volúmenes se divide en un apartado de ingresos, otro de gastos y unas hojas finales de dudas que eran anuladas conforme se clarificaban las cuestiones relativas a los pagos pendientes. La mayoría de estos registros son similares en cuanto al orden y a la tasación, y tan solo se añadían los cambios sustanciales de una colecta a otra. Por lo que aquí nos interesa, comienzan siempre con la tasa del obispo y las principales dignidades de la catedral y de Santa María la Mayor, incluidas las capellanías. Siguen el resto de las parroquias de la ciudad, después aparecen las parroquias y digni-

${ }^{24}$ Véase la seriación de las décimas de este periodo en TELLO, 2020: 108-122. MORELLÓ, 2011a: 167-173. SÁNCHEZ, 1995: 1277-1296.

${ }_{25}$ Para observar este cambio de percepción desde la última década del siglo XIV y durante los primeros años del siglo siguiente, remito a MORELLÓ, $2011 \mathrm{~b}$.

${ }_{26}$ Sobre la figura del maestre racional como auditor de las cuentas regias, véase como obra de referencia los estudios de MONTAGUT, 1987: 350-378. Para una aproximación al proceso de audición de cuentas de las décimas desde el punto de vista fiscal y contable: TELLO, 2019a.

${ }^{27}$ La documentación referente a la décima de 1278 se conserva en el Archivo Apostólico Vaticano y fue transcrita por J. Rius Serra (RIUS, 1946, vol. II: 93-121). El resto de los registros se conservan en el Archivo de la Corona de Aragón y permanecen inéditos: ACA, RP, décimas, reg. 1801 (décima de 1355); reg. 1901 (décima de 1397); y reg. 1935 (décima de 1456). 
dades de la parte foránea y, por último, las rectorías y demás dignidades de los arciprestazgos de Belchite, Daroca y Teruel.

En última instancia, previamente al análisis sistemático de los datos, deben ponerse de relieve tres ideas que se irán desarrollando a lo largo de las siguientes páginas. Por una parte, se observa que, desde los primeros libros de tasas conservados y hasta finales del siglo XIV o comienzos del siglo XV, hubo un aumento considerable del número de beneficios, sobre todo menores. Obviamente, un punto de inflexión lo marcaron las décadas posteriores a la Peste Negra, cuando parecen proliferar beneficios de altar y capellanías, a la par que muchos de ellos quedaron vacantes o desprovistos de titular ${ }^{28}$. Por otra parte, y en relación con lo anterior, desde el segundo tercio del siglo XIV y, sobre todo, a lo largo del siglo $\mathrm{XV}$, se produjo una progresiva acumulación de beneficios por parte de muchos eclesiásticos. En particular, son fundaciones de pequeña dotación que disfrutaba un mismo religioso con la pretensión, generalmente, de obtener unas rentas suficientes para su sustento ${ }^{29}$. Finalmente, cabe destacar un número relativamente amplio de beneficios exentos de pago: en los libros de cuentas, un «nichil solvit» junto a la tasa contributiva nos indica que su tributación no fue efectiva. En muchos casos era así porque no llegaban al mínimo de renta, estipulado en 20 libras anuales ${ }^{30}$; en otras ocasiones, el titular estaba exento al haber ya contribuido o por pertenecer al cardenalato o disponer de algún privilegio ${ }^{31}$.

${ }^{28}$ Como resultado de la Peste Negra y sus rebrotes, también mermó el número de eclesiásticos en la diócesis, razón por la cual aumentaron los beneficios vacantes: KERN, 1969: 71-85. Para profundizar en cómo afectó la peste a los eclesiásticos zaragozanos y aragoneses, véanse los estudios de TRENCHS, 1972. PUEYO, 1993.

${ }^{29}$ En las siguientes páginas se documentan algunos eclesiásticos que ostentaban varios beneficios a la vez y que, aun así, tenían unas rentas más bien modestas. Sin embargo, también hay ocasiones en las que la acumulación de beneficios tenía otro cariz más allá del propio sustento; es el caso, por ejemplo, de los numerosos beneficios que, de manera simultánea, podía disponer un obispo o un miembro de la alta clerecía como resultado de concesiones extraordinarias o graciosas. Todo esto también era gestionado desde la administración diocesana y tan solo haciendo uso de documentación propiamente eclesiástica, como los registros de Actos Comunes de la diócesis, sería posible individualizar cada caso: PUEYO, 1993: 706.

${ }^{30}$ Así parece ser que quedó establecido en un decreto del papa Juan XXII en 1333 y que fue confirmado en las décadas sucesivas (AAV, Registro Aviñonense, 43, f. 571v. cf. LCJXXII, doc. 60523). Tal como explica J. Morelló para el obispado de Barcelona, se produjo un aumento de beneficios simples con una dotación escasa que, en un principio, hacía que quedasen fuera de la tributación ordinaria al no alcanzar la cantidad mínima de 20 libras: MORELLÓ, en prensa. Esta realidad también se observa en otras diócesis, como Mallorca, estudiada desde una perspectiva similar (TELLO, 2019b: 112-117).

${ }^{31}$ En todas las bulas de concesión se hace alusión a que no tributaban en el impuesto ni los cardenales, ni los eclesiásticos de las órdenes militares ni las mendicantes. 
TABla 1. Tasación de las principales dignidades de la Seo y Santa María la Mayor (1280-1456)

\begin{tabular}{|c|c|c|c|c|}
\hline Dignidad & Dec. 1280 & Dec. 1355 & Dec. 1397 & Dec. 1456 \\
\hline Arzobispo & 7.000 l.j. & 4.000 l.j. & 4.000 l.j. & 9.824 l.j. \\
\hline Arcediano (La Seo) & - & 406 1. 19 s. 2 d.j. & 406 1. 19 s. 2 d.j. & 387 1.j. aprox. \\
\hline Camarero (La Seo) & $161.1 \mathrm{~s} . \mathrm{j}$. & 468 l.j. & 468 1.j. & 153 l.j. aprox. \\
\hline $\begin{array}{l}\text { Camarero (Santa } \\
\text { María la Mayor) }\end{array}$ & 147 1. 5 s.j. & 103 1. 10 s.j. & 103 1. 10 s.j. & 205 1. 13 s.j. \\
\hline Capellán (La Seo) & 36 1. 3 s.j. & - & 91.10 s.j. & 47 1.j. \\
\hline $\begin{array}{l}\text { Capellán (Santa } \\
\text { María la Mayor) }\end{array}$ & 25 1.j. & 19 l. 2 s.j. & 19 1. $2 \mathrm{s.j}$. & 33 l. $18 \mathrm{s.j}$. \\
\hline Sacristán (La Seo) & - & 260 l. 4 s. 8 d.j. & 260 1.j. & 157 1. j. aprox \\
\hline $\begin{array}{l}\text { Sacristán (Santa } \\
\text { María la Mayor) }\end{array}$ & 12 1. 2 s.j. & 201.5 s.j. & $201.5 \mathrm{s.j}$. & 20 1. 4 s.j. \\
\hline Cantor (La Seo) & 95 l.j. & 60 l.j. & 60 l.j. & 153 l.j. \\
\hline $\begin{array}{l}\text { Cantor (Santa María } \\
\text { la Mayor) }\end{array}$ & $7 \mathrm{l} . \mathrm{j}$. & - & 41.5 s.j. & 81.10 s.j. \\
\hline Enfermero (La Seo) & 2261.11 s.j. & 160 l. 11 s.j. & 160 1. 11 s.j. & 66 1.j. aprox \\
\hline $\begin{array}{l}\text { Enfermero (Santa } \\
\text { María la Mayor) }\end{array}$ & 301.7 s.j. & 65 l. 2 s. 6 d.j. & 45 1. 2 s. 5 d.j. & 421.10 s.j. \\
\hline Limosnero (La Seo) & 67 1.j. & 158 1. 3 s. 6 d.j. & 108 1. 3 s. 6 d.j. & 143 l.j. aprox. \\
\hline $\begin{array}{l}\text { Limosnero (Santa } \\
\text { María la Mayor) }\end{array}$ & - & $311.10 \mathrm{s.j}$. & & 101.5 s.j. \\
\hline Operario (La Seo) & 123 l. 3 s.j. & 2171.10 s.j & $2171.10 \mathrm{s.j}$ & 135 1.j. aprox. \\
\hline $\begin{array}{l}\text { Operario (Santa } \\
\text { María la Mayor) }\end{array}$ & - & 80 l.j & 70 1.j. & 100 1.j. \\
\hline Hospitalero (La Seo) & - & - & - & - \\
\hline $\begin{array}{l}\text { Hospitalero (Santa } \\
\text { María la Mayor) }\end{array}$ & $191.1 \mathrm{s.j}$. & - & $361.10 \mathrm{s.j}$. & - \\
\hline Prior (La Seo) & - & 190 l.j & 190 l.j. & 607 l.j. \\
\hline $\begin{array}{l}\text { Prior (Santa María la } \\
\text { Mayor) }\end{array}$ & 110 l.j. & 65 l. 12s.j & 45 l. 12 s.j. & 138 1. 12 s.j. \\
\hline
\end{tabular}

\section{Las principales dignidades del obispado}

Habida cuenta de todo ello, cada libro de cuentas comienza con la tasación de las principales dignidades catedralicias. En primer lugar, se documenta al obispo de Zaragoza, Pedro Garcés de Jaunas (1272-1280), 
contribuyendo a la décima de 1279 con 7.000 libras jaquesas ${ }^{32}$. En las tasaciones posteriores, y una vez erigida Zaragoza como sede archidiocesana independiente de la tarraconense, los arzobispos estuvieron valorados en 4.000 libras jaquesas ${ }^{33}$. Así aparece tanto en la décima de 1355, momento en el que era mitrado Lope Fernández de Luna (1352-1382) ${ }^{34}$, como en la de 1397. En esta última colecta, sin embargo, el arzobispo García Fernández de Heredia (1383-1411) no tributó porque era colector general de la décima y, por lo tanto, estaba exento ${ }^{35}$. Con la revisión de tasas de mediados del siglo XV, la riqueza del arzobispo Dalmau de Mur (1431-1456) aumentó de nuevo hasta las 9.824 libras, lo que suponía contribuir al impuesto de la décima con 982 libras anuales ${ }^{36}$.

Entre las siguientes dignidades eclesiásticas que se documentan en la ciudad destaca, por ejemplo, el camarero. Como es sabido, el camarero era el encargo de custodiar las cuentas de la comunidad catedralicia y proveer a los canónigos. En Zaragoza había dos camareros principales: el de la Seo y el de Santa María la Mayor. El camarero de la catedral de San Salvador estaba valorado en las décimas de 1355 y de 1397 con 468 libras jaquesas, si bien estuvo exento en ambas colectas: primero, porque el eclesiástico que ostentaba dicho cargo en 1355 era cardenal ${ }^{37} \mathrm{y}$, segundo, porque el camarero de la Seo en 1397 era, nada más y nada menos, que Pedro Martínez de Luna, el papa Benedicto XIII ${ }^{38}$. En la décima de 1456, la tasación del camarero catedralicio menguó hasta las 153 libras jaquesas, aunque tampoco tributó por estar exento, tal como parece extraerse de un privilegio del papa Calixto III $^{39}$. Por su parte, el camarero de Santa María la Mayor estaba tasado tanto en la décima de 1355 como en la de 1397 con 103 libras y 10 sueldos jaqueses, aunque en esta última colecta tam-

32 RIUS, 1946: 93 (AAV, Coll. 25, f. 216r).

${ }^{33}$ La archidiócesis de Zaragoza se constituyó como propia e independiente de la tarraconense en 1318: GOÑI, 1954: 87-92.

${ }^{34}$ ACA, RP, décimas, reg. 1801, f. $1 \mathrm{r}$.

35 ACA, RP, décimas, reg. 1901, f. 1r.

36 ACA, RP, décimas, reg. 1935, f. 1r. La tasa del arzobispo aumentó seguramente debido a los numerosos beneficios que disponía en varios territorios de la diócesis. Esta tendencia al alza también se observa, por ejemplo, en las rentas del obispo de Barcelona que llegó a disponer de unas 1.600 libras barcelonesas en 1456 (MORELLÓ, en prensa).

${ }^{37}$ ACA, RP, décimas, reg. 1801, f. $1 \mathrm{r}$.

38 ACA, RP, décimas, reg. 1901, f. $2 \mathrm{v}$.

39 ACA, RP, décimas, reg. 1935, f. 2v. Desconozco si esta rebaja de la tasa se produjo justo en las revisiones de la década de 1440 o ya se documenta a comienzos del siglo XV cuando, parece ser, se realizaron pequeños reajustes a la hora de actualizar las tasas para otros subsidios particulares (DOMINGO-GUTIERREZ, 1999: 413-450). En todo caso, en la décima de 1408 el camarero todavía seguía tasado con las 468 libras ya mencionadas (ACA, RP, décimas, reg. 1906, f. 1v). 
bién estuvo dispensado ${ }^{40}$. En la décima de 1456 su valoración ascendió a 205 libras, seguramente debido a la disposición de otros beneficios en la diócesis ${ }^{41}$.

Con unas rentas bastante elevadas también se documenta al arcediano de la catedral, tasado con 406 libras, tanto en la décima de 1355 como en la de 1397, si bien en el primer caso, el eclesiástico estuvo exento porque disponía del título cardenalicio ${ }^{42}$. Con la revisión de tasas de mediados de siglo XV, el arcediano también disminuyó su riqueza en casi 20 libras, hasta las $387^{43}$. Del mismo modo, el sacristán de la catedral tenía una renta de 260 libras en los años 1355 y 1397, pero su rédito también menguó hasta las 157 libras en la décima de 1456, momento en el que no se le documenta ninguna otra prepositura más allá de la sacristía ${ }^{44}$. Por su parte, en la décima de 1279 , el enfermero catedralicio estaba tasado con 226 libras por la enfermería y la vicaría de la catedral ${ }^{45}$. En las recaudaciones posteriores, la tasa del enfermero disminuyó hasta 160 libras, si bien en la décima de 1397 el enfermero estuvo exento por ostentar también la dignidad cardenalicia ${ }^{46}$.

Con estos ejemplos se observa que no todas las dignidades eclesiásticas tuvieron una evolución similar a lo largo de la Baja Edad Media y que su crecimiento o disminución estuvo ligado, directamente, a la bonanza o al empobrecimiento de los beneficios que disfrutaban, así como al número de entes que disponían. En general, las principales dignidades de la catedral y de la iglesia de Santa María la Mayor percibían unas rentas que, desde finales del siglo XIII y hasta la revisión de mediados del siglo XV, suponían en torno al 40-45\% del total del obispado. Sin embargo, documentamos un punto de inflexión en la décima de 1456, cuando la tributación de estas dignidades disminuyó hasta un $25 \%$. Un descenso tan drástico puede ser debido, en parte, a un mayor control del número de los aniversarios, beneficios y preposituras del resto de la diócesis. Dicho de otro modo, si bien muchas de estas fundaciones aparecían ya en las recaudaciones anteriores, no fue hasta mediados del siglo XV cuando se tasaron escrupulosamente ${ }^{47}$.

40 ACA, RP, décimas, reg. 1801, f. 1v (décima de 1355); reg. 1901, f. 9r (décima de 1397).

${ }^{41}$ ACA, RP, décimas, reg. 1935, f. $17 \mathrm{v}$.

${ }^{42}$ ACA, RP, décimas, reg. 1801, f. 1r; reg. 1901, f. 1v.

43 ACA, RP, décimas, reg. 1935, f. 2r. Quizá esto sea debido a que, en las décimas anteriores, el arcediano ocupaba alguna de las preposituras catedralicias; sin embargo, en la décima de 1456 ya no se alude a esta cuestión.

${ }^{44}$ De hecho, era habitual que la jerarquía diocesana recibiese también rentas de las preposituras catedralicias. Con respecto la décima de 1355: ACA, RP, décima, reg. 1801, f. 1r. En relación con la décima de 1397: ACA, RP, décima, reg. 1901, f. 1v. Los datos de estas dignidades en la décima de 1456 se encuentran en ACA, RP, décima, reg. 1935, f. 1v y 2r.

45 SERRA, 1946: 93 (AAV, Coll. 25, f. 216r).

46 ACA, RP, décimas, reg. 1901, f. 3r.

47 En la décima de 1280, las principales dignidades eclesiásticas estaban valoradas con un $45 \%$ del monto total de las décimas, mientras que en la décima de 1355 la cantidad era de 44\% 
En todo caso, tampoco se puede atestiguar si tras estas fluctuaciones de las tasas decimales hubo un cambio real en las cantidades percibidas para el sustento de los beneficios; además, por otra parte, también se debe tener en cuenta el número de beneficios exentos a la hora de hacer estos cálculos porcentuales. Dicho de otro modo, esto no entra en oposición con la hipótesis de que, en el caso de la décima de 1456, sí que parece existir una transferencia de renta eclesiástica hacía algunas dignidades catedralicias. En particular, se observa cómo las rentas procedentes del antiguo arcedianato de Belchite fueron contabilizadas junto a los principales eclesiásticos del resto de arcedianatos $\mathrm{y}$, sobre todo, canónigos diocesanos. Y es que, parece ser que a mediados del siglo XV se documenta una incautación temporal de las rentas del arcedianato de Belchite «ex post vero exmembris segregatis ex archidiaconatum Belchiten fructum $»^{48}$.

\section{Las capellanías de la Seo y Santa María la Mayor}

Una cuestión algo más alejada de la temática propiamente fiscal, pero que nos aporta una información muy relevante en cuanto a la tasación de los beneficios, son los datos referidos a las capellanías de los principales centros de la ciudad. Las capellanías son fundaciones perpetuas sustentadas mediante unos bienes o rentas que disponía el fundador, a través del cual un eclesiástico podía atender las diversas cargas espirituales que le fueron conferidas (misas, mantenimiento del altar u otras causas pías). La dotación de cada una de ellas y el sustento del eclesiástico que estaba al frente dependía de la capacidad económica del oferente y del patrono, de acuerdo con lo estipulado en el testamento del fundador. De todos modos, el número de capellanías fue creciendo a lo largo y ancho de los centros religiosos durante el siglo XIII y hasta bien entrado el siglo XIV.

\footnotetext{
y en la décima de 1397 descendió hasta el 40\%. Sin embargo, tal como puede verse en la tabla, debemos ser cautos a la hora de establecer estos porcentajes ya que la contribución efectiva y real fue algo menor debido al elevado número de beneficios exentos y a una tasación más escrupulosa de capellanías de otros centros religiosos. Así, por ejemplo, en la décima de 1397 , tal solo el $20 \%$ de las altas dignidades de la catedral contribuyeron al impuesto, ya que tanto el arzobispo, como el camarero o el enfermero, cuyas rentas en conjunto ascendían hasta 4.970 libras jaquesas, estaban exentos del pago (ACA, RP, décimas, reg. 1901, f. 1r; 2v; 3r.).

48 Este es el caso del sacristán de la Seo, a quien en 1456 se le aumentó en 1.000 sueldos su tasación al incluir los frutos procedentes del arcedianato de Belchite (ACA, RP, décimas, reg. 1935, f. 1v.). Algo similar sucedió con el arcediano de Teruel, quien de estar tasado con 4.842 sueldos pasó a 5.242 sueldos a mitad del siglo XV (ACA, RP, décimas, reg. 1935, f. 2r) o el limosnero de la catedral de Zaragoza, al que también le fueron añadidos 500 sueldos a su renta ordinaria (ACA, RP, décimas, reg. 1935, f. 3r). En todo caso, este es un tema aún por estudiar y resulta de vital importancia para valorar la evolución general de la tributación de estas dignidades.
} 
TABla 2. Capellanías documentadas en la Seo y en Santa María la Mayor en la décima de 1397

\begin{tabular}{|c|c|c|c|}
\hline Capellanías de la Seo & Tasa & $\begin{array}{c}\text { Capellanías de Santa María la } \\
\text { Mayor }\end{array}$ & Tasa \\
\hline $\begin{array}{l}\text { Capellanía de Berenguer de } \\
\text { Flumano }\end{array}$ & $71.10 \mathrm{s.j}$ & Capellanía de Juan de Muro & Exenta \\
\hline $\begin{array}{l}\text { Capellanía de Berenguer de } \\
\text { Fontova }\end{array}$ & Exenta & $\begin{array}{l}\text { Capellanía de Alamán de } \\
\text { Baldoví }\end{array}$ & Exenta \\
\hline $\begin{array}{l}\text { Capellanía de Berenguer de } \\
\text { Torrellas }\end{array}$ & $41.10 \mathrm{s.j}$. & $\begin{array}{l}\text { Capellanía de Bartolomé de } \\
\text { Eslava }\end{array}$ & Exenta \\
\hline $\begin{array}{l}\text { Capellanía de Bernardo de } \\
\text { Mauleón }\end{array}$ & Exenta & Capellanía de Fernando Buisán & $21.10 \mathrm{s.j}$. \\
\hline $\begin{array}{l}\text { Capellanía de Domingo del } \\
\text { Castellar }\end{array}$ & Exenta & Capellanía de Ferrer de Lanuza & Exenta \\
\hline $\begin{array}{l}\text { Capellanía de Guerau de } \\
\text { Saprato }\end{array}$ & $91 . j$. & $\begin{array}{l}\text { Capellanía de García de } \\
\text { Marcuello }\end{array}$ & Exenta \\
\hline $\begin{array}{l}\text { Capellanía de Guillermo de la } \\
\text { Fondiga }\end{array}$ & Exenta & Capellanía de Jaime de Épila & 5 1.j. \\
\hline Capellanía de Jimeno de Luna & $121.10 \mathrm{s.j}$ & Capellanía de Jimeno de Salanova & Exenta \\
\hline Capellanía de Juan de Ferreruela & Exenta & Capellanía de Juan de Belloch & Exenta \\
\hline $\begin{array}{l}\text { Capellanía de Lope de Castellar } \\
\text { e Íñigo de Pomar }\end{array}$ & Exenta & Capellanía de Lope de Aínsa & Exenta \\
\hline Capellanía de Maria de Seyrón & Exenta & Capellanía de Martín de Sigüenza & Exenta \\
\hline $\begin{array}{l}\text { Capellanía de Nicolau de } \\
\text { Capiella }\end{array}$ & 10 1.j. & Capellanía de Miguel de Sesa & 81.10 s.j. \\
\hline Capellanía de Oriol Clavera & Exenta & $\begin{array}{l}\text { Capellanía de Pedro Martínez } \\
\text { de Luna }\end{array}$ & 10 l.j. \\
\hline Capellanía de Pascasio Gordo & 7 1.j. & & \\
\hline $\begin{array}{l}\text { Capellanía de Pascasio de } \\
\text { Gomar }\end{array}$ & 4 1.j. & & \\
\hline Capellanía de Pedro de Cieza & Exenta & & \\
\hline Capellanía de Pedro de Líbrana & 48 1.j. & & \\
\hline $\begin{array}{l}\text { Capellanía de Pedro Jiménez de } \\
\text { Aranda }\end{array}$ & Exenta & & \\
\hline $\begin{array}{l}\text { Capellanía de Pedro Jiménez de } \\
\text { Ayerbe }\end{array}$ & Exenta & & \\
\hline $\begin{array}{l}\text { Capellanía de Pedro López de } \\
\text { Eslava }\end{array}$ & 5 1.j. & & \\
\hline Capellanía de Vital de Castellar & Exenta & & \\
\hline Capellanía de Vital Sallent & $61 . j$ & & \\
\hline Total aprox. & 114 1.j. & Total aprox. & 26 1.j. \\
\hline
\end{tabular}


Tabla 3. Capellanías documentadas en la Seo y en Santa María la Mayor en la décima de 1456

\begin{tabular}{|c|c|c|c|}
\hline Capellanías de la Seo & Tasa & $\begin{array}{c}\text { Capellanías de Santa María } \\
\text { la Mayor }\end{array}$ & Tasa \\
\hline $\begin{array}{l}\text { Capellanía de Bartolomé y Juan } \\
\text { Invictos }\end{array}$ & 7 s.j. & $\begin{array}{l}\text { Capellanía de Jimeno de } \\
\text { Salanova }\end{array}$ & 4 1. 11 s.j. \\
\hline $\begin{array}{l}\text { Capellanía de Berenguer de } \\
\text { Flumano }\end{array}$ & $121.7 \mathrm{s.j}$. & $\begin{array}{l}\text { Capellanía de Alamán de } \\
\text { Baldoví }\end{array}$ & $111.5 \mathrm{s.j}$. \\
\hline $\begin{array}{l}\text { Capellanía de Berenguer de } \\
\text { Fontova }\end{array}$ & Exenta & Capellanía de Catalina Donat & 51.4 s.j. \\
\hline $\begin{array}{l}\text { Capellanía de Berenguer de } \\
\text { Torrellas }\end{array}$ & 5 1. 5 s.b. & $\begin{array}{l}\text { Capellanía de Domingo Cerdán } \\
\text { y María Sanchez de Aliaga }\end{array}$ & 25 l.j. \\
\hline Capellanía arzobispal & 20 l.j. & Capellanía de Donelfa de Gurrea & 20 1.j. \\
\hline Capellanía de Domingo de Biota & 221.10 s.j. & $\begin{array}{l}\text { Capellanía de Juan Donelfa de } \\
\text { Luna }\end{array}$ & 25 1.j. \\
\hline $\begin{array}{l}\text { Capellanía de Domingo del } \\
\text { Castellar }\end{array}$ & 10 1. 5 s.j. & Capellanía de Elvira Pérez & $101.1 \mathrm{s.j}$. \\
\hline Capellanía de Esteban Gil & 61.10 s.j. & Capellanía de Fernando Buisán & 161.5 s. j. \\
\hline $\begin{array}{l}\text { Capellanía de Garcia Jimeno de } \\
\text { Aresa }\end{array}$ & $61.10 \mathrm{s.j}$ & $\begin{array}{l}\text { Capellanía de Fernando de } \\
\text { Lanuza }\end{array}$ & $\begin{array}{c}291.17 \mathrm{~s} . \\
\text { j. }\end{array}$ \\
\hline Capellanía de Gerau de Saprato & $31.15 \mathrm{s.j}$. & Capellanía de García de Marcuello & 11 1. 2 d.j. \\
\hline $\begin{array}{l}\text { Capellanía de Guillermo de la } \\
\text { Fondiga }\end{array}$ & $31.15 \mathrm{~s} . j$. & Capellanía de Isabel Ram & 17 1. $10 \mathrm{s.j}$ \\
\hline Capellanía de Guillermo de Binacha & Exenta & Capellanía de Jaime de Épila & 71.10 s.j. \\
\hline Capellanía de Íñigo de Pomar & $11 . j$. & Capellanía de Jimenez de Urrea & $51 . \mathrm{j}$. \\
\hline Capellanía de Jimeno de Luna & $10113 \mathrm{s.j}$. & Capellanía de Juan de Belloch & $\begin{array}{c}201.12 \\
\text { s.j. }\end{array}$ \\
\hline $\begin{array}{l}\text { Capellanía de Juan de } \\
\text { Ferreruela }\end{array}$ & 8 1.j. & $\begin{array}{l}\text { Capellanía de Juan Lope de } \\
\text { Gurrea }\end{array}$ & 131.9 s.j. \\
\hline Capellanía de Juan Ortíz de Fuentes & $151.8 \mathrm{s.j}$ & Capellanía de Lope de Aínsa & $\begin{array}{c}91.20 \mathrm{s.} 6 \\
\mathrm{~d} . \mathrm{j}\end{array}$ \\
\hline Capellanía de Lope de Castellar & $71 . j$. & Capellanía de María de Aranda & $111 . \mathrm{j}$. \\
\hline Capellanía de Martin de Canaldos & 61.10 s.j. & Capellanía de María Gilbert & $251 . j$. \\
\hline $\begin{array}{l}\text { Capellanía de Mengia de } \\
\text { Novallas }\end{array}$ & $91.1 \mathrm{s.j}$ & $\begin{array}{l}\text { Capellanía de María Jímena } \\
\text { Torreziella }\end{array}$ & $171.16 \mathrm{s.j}$ \\
\hline Capellanía de Nicolau de Capiella & $101.18 \mathrm{s.j}$. & Capellanía de Miguel de Sesa & 7 1. 10 s.j. \\
\hline Capellanía de Pascasio Gordo & $161.4 \mathrm{s.j}$. & & \\
\hline Capellanía de Pascasio de Gomar & $21.2 . s . j$. & & \\
\hline Capellanía de Pedro Aylés & $61 . j$. & & \\
\hline Capellanía de Pedro Daroca & 131.10 s.j. & & \\
\hline Capellanía de Pedro de Silana & $41.18 \mathrm{s.j}$. & & \\
\hline $\begin{array}{l}\text { Capellanía de Pedro Estefano } \\
\text { Pentinat }\end{array}$ & 25 1.j. & & \\
\hline $\begin{array}{l}\text { Capellanía de Pedro Jimenez de } \\
\text { Rueda }\end{array}$ & 10 l. 4 s.j. & & \\
\hline
\end{tabular}




\begin{tabular}{|l|c|c|c|}
\hline \multicolumn{1}{|c|}{ Capellanías de la Seo } & Tasa & $\begin{array}{c}\text { Capellanías de Santa María } \\
\text { la Mayor }\end{array}$ & Tasa \\
\hline Capellanía de Pedro Miguel & $61.10 \mathrm{s.3 \textrm {d } . j .}$ & & \\
\hline Capellanía de San Antonio & $61.13 \mathrm{s.j.}$ & & \\
\hline $\begin{array}{l}\text { Capellanía de Sancho Ortíz de } \\
\text { Fuentes }\end{array}$ & $161.8 \mathrm{s.j.}$ & & \\
\hline Capellanía de Sibila Brun & $71 . \mathrm{j}$. & & \\
\hline Capellanía de Vital del Castellar & $151.10 \mathrm{s.j.}$ & & $2931.7 \mathrm{s.j.}$ \\
\hline Total aprox. & $2901.16 \mathrm{s.j.}$ & Total aprox. & \\
\hline
\end{tabular}

En este caso, se han tomado como referencia las capellanías adscritas a la catedral y a Santa María la Mayor en 1397 y 1456 debido a los datos excepcionales de que se dispone para ambos centros durante estas colectas ${ }^{49}$. Según la décima de 1397, la Seo contaba con veintidós capellanías y Santa María la Mayor con trece. En la décima de 1456, su número aumentó un 32\%; esto es, hasta treinta y dos capellanías en la catedral y veinte en Santa María la Mayor. A efectos fiscales, este cambio se tradujo en que la valoración del conjunto de fundaciones de la Seo se situaba en torno a las 114 libras en 1397 para ascender hasta las 290 libras en 1456. Por su parte, de las 26 libras que sumaban las capellanías de Santa María la Mayor a finales del siglo XIV, se pasó a 293 libras a mediados del siglo siguiente. Al analizar las cuentas de la décima de 1456 se observa que la dotación media también aumentó de forma notoria. En particular, en 1456 se documentan quince capellanías con una dotación situada entre 15 y 25 libras, mientras que la media habitual de la décima de 1397 era de unas ocho o nueve libras y, tan solo una, superaba las diez libras ${ }^{50}$. En última instancia, más allá del aumento de su número, la elevada contribución se debe también a que en la décima de 1456 no parece haber capellanías exentas de pago en Santa María la Mayor y tan solo había dos exoneradas en la catedral por no llegar al mínimo contributivo ${ }^{51}$.

Como se ha indicado, muchas de las capellanías a las que aquí nos referimos tienen su origen a finales del siglo XIII. Algunas de estas fueron instituidas por conocidos religiosos aragoneses, otras por nobles y caballeros e, incluso, también por laicos y ciudadanos honrados con una destacada presencia en la ciudad.

49 Como un estudio de caso de la situación de la mensa episcopal y las capellanías de la Seo a finales del siglo XIII, véase: GUTIÉRREZ, 1980: 7-116.

${ }^{50}$ En 1307, tan solo la fundación del arzobispo Jimeno de Luna, adscrita a la Seo, tenía una renta de 12 libras; el resto se sitúan por debajo de las 10 libras: ACA, RP, décimas, reg. 1901, f. $5 \mathrm{v}$.

51 ACA, RP, décimas, reg. 1935, f. 10 v. Sin embargo, según la décima de 1397, nada más y nada menos que doce capellanías de la Seo y nueve de Santa María la Mayor estaban exentas; es decir solo tributaban un $61 \%$ de las fundaciones de la catedral de San Salvador y el 45\% de Santa María la Mayor. 
Entre aquellas erigidas por eclesiásticos, destaca la capellanía perpetua del obispo Pedro de Librana, si bien seguramente fue fundada por su sucesor, el mitrado Pedro Tarroja, a finales del siglo XII. Según la décima de 1397, la capellanía arzobispal era administrada por seis beneficiados que, con el fin de cumplir con las misas y el mantenimiento del culto, recibían anualmente unas rentas — nada desdeñables - de 48 libras. En particular, uno de los beneficiados de dicha capellanía era Pedro Ram, que llegó a ser prior de la Seo en los albores del siglo XV; y otro era Domingo Manent, un capellán que disponía en este periodo de otras rentas en la ciudad ${ }^{52}$. En segundo lugar, otra capellanía arzobispal, la de Jimeno de Luna, estaba custodiada, según la décima de 1397, por dos eclesiásticos de la Seo, Pedro Simón y Jimeno San Vicente, para lo cual también disponían de una renta de 12 libras $^{53}$.

Más allá de estas fundaciones, es posible enumerar un sinfín de capellanías promovidas por otros eclesiásticos que desempeñaron funciones destacadas en la catedral o Santa María, tales como la de Berenguer de Fontova, Berenguer de Flumano o Miguel de Sesa. La de Berenguer de Fontova se erigió, parece ser, en honor al homónimo arcediano de catedral que formaba parte de la mensa capitular en $1293^{54}$. Sin embargo, ni en la décima de 1397 ni en la de 1456 tuvo una contribución efectiva porque - parece ser - no llegaba al mínimo tributario ${ }^{55}$. En cambio, sí que contribuyó el beneficiado de la capellanía del canónigo Berenguer de Flumano, sustentada en 1397 por Arnaldo Langart y tasada en siete libras y diez sueldos jaqueses ${ }^{56}$. En la Seo destaca también la capellanía de otro camarero catedralicio que fundó una capellanía en el siglo XIII, Pascasio Gordo ${ }^{57}$. En 1397, este beneficio disponía de una renta anual de 11 libras y 10 sueldos, aunque estaba exento $^{58}$, y en 1456 tenía establecida una renta de 16 libras y 4 sueldos $^{59}$. Por su parte, en Santa María la Mayor documentamos la capellanía de Miguel de Sesa. Miguel de Sesa fue un camarero de la colegiata y fundó un beneficio en el altar

52 ACA, RP, décimas, reg. 1901, f. 7v. Por ejemplo, en 1394, el papa Benedicto XIII reservó a Manent, capellán de la Seo, un beneficio de colación del arzobispo, prior y capítulo de la Iglesia de Zaragoza (CUELLA, 2003, doc. 418).

53 ACA, RP, décimas, reg. 1901, f. 5v. Medio siglo más tarde, la capellanía estaba en manos de otros dos beneficiados, tasados en su conjunto con 12 libras (ACA, RP, décimas, reg. 1935, f. $11 v-12 r)$.

54 ACA, RP, décimas, reg. 1901, f. 5v (véase GUTIÉRREZ, 1980: 35-36).

55 ACA, RP, décimas, reg. 1935, f. 10v.

56 ACA, RP, décimas, reg. 1901, f. 6r. Unas décadas después, según la décima de 1456, la misma capellanía estaba valorada en 12 libras y 7 sueldos (ACA, RP, décimas, reg. 1935, f. 10v).

${ }^{77}$ En particular, parece ser que esta capellanía ya existía desde entonces: LALIENA, 2010: 69-70, 84 .

${ }^{58}$ ACA, RP, décimas, reg. 1901, f. 4v. El eclesiástico beneficiado de esta fundación era Miguel de Bolea.

${ }_{59}$ ACA, RP, décimas, reg. 1935, f. 10r.

Hispania, 2021, vol. LXXXI, n. ${ }^{\circ}$ 267, enero-abril, págs. 11-43, ISSN: 0018-2141, e-ISSN: 1988-8368 https://doi.org/10.3989/hispania.2021.001 
mayor en $1307^{60}$. En las décimas de 1397 y 1456 los eclesiásticos que regían tal beneficio estaban tasados con ocho y siete libras respectivamente ${ }^{61}$.

No solo eclesiásticos que habían desempeñado buena parte de su carrera eclesiástica en estos centros religioso fundaron capellanías en la Seo o Santa María. Un amplio número de clérigos que dispusieron de cargos en otros centros también erigieron fundaciones en la Seo. Este es el caso, por ejemplo, de Vital de Castellar. En particular, parece ser que este arcediano de Belchite había instaurado dos capellanías ya a finales del siglo XIII y que, además, había contribuido al sustento de los primeros escolares pobres que estudiaban en la catedral ${ }^{62}$. A comienzos del siglo XV uno de los beneficiados de esta fundación fue Pedro Palomar, aunque parece ser que, poco después, el papa Benedicto XIII intentó promover al mismo beneficio al racionero de la iglesia parroquial del lugar de Luna, Antonio Arnaldo ${ }^{63}$.

Dejando de lado las capellanías instituidas por eclesiásticos, también documentamos un amplio número de fundaciones que realizaron nobles, caballeros o ciudadanos honrados de Zaragoza. Más allá de la perpetuación de la memoria, no cabe menospreciar la importancia que adquirió la inversión en rentas eclesiásticas por parte del poder ciudadano zaragozano. Por ello, no es extraño documentar en numerosas mandas testamentarias la dotación de capellanías o de aniversarios en los principales centros religiosos de la ciudad. En el caso zaragozano, esta realidad ha sido ampliamente documentada para linajes como los Palomar, pero lo mismo podríamos decir de un nutrido grupo de familias como los Salanova, los Castellar, los Marcuello, los Torrellas o los Buisán, entre otros ${ }^{64}$.

${ }^{60}$ CASORRÁN, 2016: 380.

${ }^{61}$ ACA, RP, décimas, reg. 1901, f. 10r; reg. 1935, f. 20v. En particular, en la décima de 1397 uno de los beneficiados era Francisco de Torla, presbítero de Santa María. Asimismo, Torla también disponía de otra prepositura en la capellanía de Juan Martínez de Bruxes, canónigo de Santa María (ACA, RP, décimas, reg. 1901, f. 10v).

${ }^{62}$ Por su parte, la de Vital de Castellar estaba dotada en 1397 con 11 libras (ACA, décimas, reg. 1901, f. 2v).

${ }_{63}$ CANELLAS LÓPEZ, 1990, vol. 3, doc. 1465. MIGUEL, ANDRÉS y CASORRÁN, 2008: 495.

${ }^{64}$ Para la referencia concreta a los Palomar, véase la tesis doctoral de LOZANO, 2006: 146. Más allá de ello, remito igualmente a los estudios de S. Lozano y a obras de referencia donde se observa esta realidad: DE LA TORRE, 2018. MAINE, 2006. Para conocer el papel concreto desempeñado por estas familias a la hora de fundar capellanías sería necesario un análisis sistemático de la documentación notarial, en general, y de los testamentos y codicilos, en particular. Asimismo, en un estudio más preciso se deberían tener en cuenta las capellanías sustraídas de la jurisdicción eclesiástica y que no contribuían a los subsidios eclesiásticos y tampoco aparecían, por tanto, en los libros de tasas decimales. Sea como sea, para observar la importancia que se ha otorgado a estas fundaciones para el estudio del ascenso social y de la jerarquía urbana, véase como referencia general: BORAU, 2003. Y para la época moderna, entre otros: SORIA MESA, 2002: 135-148. 
De este modo, puede identificarse un importante número de capellanías que tenían una dotación considerable. Generalmente, muchas de ellas fueron instituidas tardíamente a finales del siglo XIV o, incluso, en algún caso puntual, ya en el siglo XV. En Santa María la Mayor, por ejemplo, a finales del siglo XIV documentamos una capellanía instituida por el Justicia de Aragón, Domingo Cerdán, y su mujer María de Aliaga, que estaba tasada con 25 libras. El Justicia Domingo Cerdán fue vecino de la parroquia de Santa María y desempeñó el cargo de Justicia de Aragón desde 1362 hasta 1389, justo dos años antes de su muerte, cuando le sucedió su hijo ${ }^{65}$. También con 25 libras anuales estaban valoradas en el mismo centro la capellanía de Juan Donelfa de Luna y María Gilbert $^{66}$. En la Seo, con 25 y 22 libras estaban valoradas, respectivamente, las capellanías de Pedro Esteban Pentinant y Domingo de Biota ${ }^{67}$. Por otra parte, con una dotación menor, 17 libras, documentamos en Santa María la Mayor, la capellanía tardía de Isabel Ram, esposa de Berenguer de Bardají, señor de la baronía oscense de Antillón ${ }^{68}$. En el mismo centro, con una valoración similar, encontramos las de María Jimena de Torreziella ${ }^{69}$ y Fernández de Buisán ${ }^{70}$.

Con todo, la mayoría de las capellanías se fundaron décadas antes y estaban dotadas con unas rentas menores a las diez libras anuales. Así, por ejemplo, una familia noble que erigió una capellanía a comienzos del siglo XIV fue la de los Aranda. En particular, se documenta en la Seo la capellanía de Pedro Jiménez de Aranda que en 1397 estaba tasada con seis libras y era regida por Pedro de Uncastillo ${ }^{71}$. Asimismo, la capellanía de Jimeno de Salanova, en Santa María la Mayor, estaba exenta de pago en 1397 y tasada con cuatro libras y once sueldos en 1456. Desconozco el momento de su fundación y su patrono, pero se sabe que en 1397 el capellán al frente de tal beneficio era Estefano

${ }^{65}$ Sobre la tasa decimal: ACA, RP, décimas, reg. 1935, f. 22v. Para las referencias al Justicia, acúdase a RODRIGO ESTEBAN, 1991: vol. 1. GONZÁLEZ ANTÓN, 2002: 170. Sobre la trayectoria familiar de Domingo Cerdán y su hijo, Juan Giménez Cerdán, véase: GIMENEZ SOLER, 1897: 337-346.

66 ACA, RP, décimas, reg. 1935, f. 22v, 23r.

67 ACA, RP, décimas, reg. 1935, f. 12v, 13v.

68 ACA, RP, décimas, reg. 1935, f. 22v. Isabel Ram pertenecía a la conocida familia de los Ram de Zaragoza; linaje que alcanzó una posición importante en la administración real, donde muchos de sus miembros fueron destacados consejeros desde el reinado de Pedro IV. Asimismo, su hermano, Domingo Ram y Lanaja, fue arzobispo de Tarragona, estuvo presente en las Cortes de 1412 y fue designado cardenal por Martin V (EUBEL, 1913: 34). Uno de los hijos de Isabel Ram y Berenguer de Bardají, Jorge Bardají, fue prior de la colegiata del Santo Sepulcro de Calatayud y obispo de Tarazona (GARCIA CIPRÉS, 1912).

${ }^{69}$ ACA, RP, décimas, reg. 1935, f. 22r.

70 ACA, RP, décimas, reg. 1935, f. 21v.

71 ACA, RP, décimas, reg. 1901, f. 4v. Como se ha indicado, posiblemente la capellanía fue instituida a comienzos del siglo XIV: NAVARRO, 2009: 66. SESMA, 1993: 385. 
Diest $^{72}$. Décadas más tarde, en 1442, esta capellanía estaba procurada por el escudero Martín Jiménez de Salanova y, en 1457, Leonor de Salanova, seguramente como patrona o procuradora, dispuso de su regencia al conocido Alamán de Baldoví73. Otra capellanía destacada era la de Jaime de Épila que estaba tasada con cinco libras en 1397 y con siete libras y diez sueldos en $1456^{74}$. En 1397 estaba regentada por Domingo de Torla, pero poco después pasó a estar vacante. De hecho, en 1402, el arzobispo zaragozano quiso otorgar este beneficio al capellán Domingo de Alcalá; sin embargo, mediante una gracia pontificia, parece ser que esta capellanía, junto a otros beneficios, fue dispuesta al eclesiástico Pascasio $\mathrm{Gea}^{75}$. Finalmente, debe indicarse que, en otras ocasiones, numerosas fundaciones instituidas por linajes relevantes de la ciudad estaban exentas. Este sería el caso de la capellanía de García de Marcuello en Santa María la Mayor, que no contribuyó ni en la décima de 1397 ni en la $1456^{76}$, o la de Juana de Muro que estaba exenta en la recaudación de la décima, sin saber a ciencia cierta la causa ${ }^{77}$.

\section{Las parroquias de la ciudad de Zaragoza}

Otros datos relevantes para el tema que aquí nos ocupa, son las tasas con las que estaban gravadas los rectores y vicarios de las principales parroquias de la ciudad. Como es sabido, Zaragoza se dividía en una serie de parroquias, que se situaban en el punto angular del gobierno urbano al derivar de ellas los principales cargos públicos, tal como señala E. Mainé. Es más, la estructura parroquial de Zaragoza fue básica y fundamental para consolidar o ampliar el poder político, y también económico, de los linajes de ciudadanos honrados durante la Baja Edad Media ${ }^{78}$. Sin pretender llevar a cabo un análisis de su importancia dentro del municipio zaragozano, en este apartado se pretende mostrar cómo evolucionó la tasación de los rectores y vicarios de las principales parroquias. En general, poco se puede indicar de momento más allá de la fosilización de las tasas decimales entre 1355 y 1397 y la revalori-

72 ACA, RP, décimas, reg. 1901, f. 11r; reg. 1935, f. 22r.

73 LOZANO, 2006: 146.

74 ACA, RP, décimas, reg. 1901, f. 10v; reg. 1935, f. 20v.

75 CUELLA, 2003: vol. 1, doc. 888 (21/08/1402).

76 ACA, RP, décimas, reg. 1901, f. 11v; reg. 1935, f. 21r.

77 En este caso, sin embargo, sí que se sabe que fue instituida en 1313, momento en el que fundó una capellanía dotada con seis sueldos anuales pagaderos al sacristán en el altar de San Juan de Santa María la Mayor: CASORRÁN, 2016: 95.

${ }^{78}$ Como un contexto general para la importancia económico-política de las parroquias en la ciudad de Zaragoza, sus funciones administrativas y los cambios que fueron fraguándose a lo largo del quinientos acúdase a DE LA TORRE, 2018. LOZANO, 2012; 2006. MAINE, 2006. 
zación de mediados del siglo XV. La fijación de las tasas a lo largo del siglo XIV y su evolución durante el siglo XV es similar a lo observado en otros centros urbanos como Barcelona o Mallorca ${ }^{79}$. En el caso de Zaragoza, y tomando como base los estudios de referencia, aquellas parroquias que disponían de una renta más alta eran las que concentraban un mayor número de vecinos y las que - a lo largo de los siglos XIV y XV- tuvieron una mayor influencia en el gobierno urbano ${ }^{80}$.

TABLA 4. La tasación de los rectores de parroquias de la ciudad de Zaragoza $(1280-1456)$

\begin{tabular}{|c|c|c|c|c|}
\hline Parroquia & Dec. 1280 & Dec. 1355 & Dec. 1397 & Dec. 1456 \\
\hline San Pablo & - & 16 l.j. & - & 28 1.j. \\
\hline San Felipe & 15 l.j. & 6 l.j. & 6 l.j. & 30 l.j. \\
\hline San Gil & exento & 4 1.j. & 4 l.j. & 15 l.j. \\
\hline Santa Cruz & - & 35 1. 3 s.j. & 5 1. 14 s.j. & - \\
\hline San Jaime & exento & 4 l.j. & 15 l.j. & 10 l.j. \\
\hline San Juan del Puente & exento & 4 1.j. & $51 . j$. & 9 1.j. \\
\hline Santa María Magdalena & 20 l.j. & 9 l.j. & 9 1.j. & 36 l.j. \\
\hline San Lorenzo & - & $51 . j$. & 5 1.j. & 6 1.j. \\
\hline San Nicolás & exento & $81 . j$. & 8 1.j. & $161 . j$. \\
\hline $\begin{array}{l}\text { San Miguel de los } \\
\text { Navarros }\end{array}$ & 30 1.j. & 15 l.j. & 15 1.j. & 34 1.j. \\
\hline San Pedro & $41 . j$ & $51 . j$ & 5 1.j. & 17 l.j. \\
\hline San Juan de los Panetes & exento & - & - & 25 1.j. \\
\hline San Andrés & exento & 5 l.j. & 5 l.j. & 15 l.j. \\
\hline San Antón & - & 31 1. 10 s. 7 d. j. & 311.10 s.j. & 16 1.j. \\
\hline San Blas & 201.9 s.j. & - & - & - \\
\hline Santa Maria de Altabás & - & $171.10 \mathrm{s.j}$. & 171.10 s.j. & $71 . j$. \\
\hline Santa María del Portillo & & - & - & 35 l.j. \\
\hline
\end{tabular}

79 Para esta cuestión remito nuevamente a MORELLÓ, en prensa. TELLO, 2019a.

${ }^{80}$ MAINÉ, 2006: 114-116. LOZANO, 2004: 471-518. Según el fogaje aragonés de 1495, por ejemplo, la parroquia de San Pablo contaba con unos 1200 fuegos, un 32\% del total de población; la Magdalena, con 347 fuegos, un 9,9\%; y San Gil y San Felipe, con unos 285 fuegos, esto es, un 7,15\% del total. Los datos están extraídos de SERRANO MONTALVO, 1995: 67 y ss. y DE LA TORRE, 2018. 
En todo caso, sí que puede ponerse de manifiesto que un amplio número de rectores y vicarios de parroquias de la ciudad (sobre todo las mayores) aumentaron su tasa contributiva a mediados del siglo XV. Así, por ejemplo, el vicario de la iglesia de la Magdalena fue tasado en la décima de 1456 con 36 libras $^{81}$, una cantidad mucho más elevada de la que tenía el vicario en la décima de 1397, cuando la vicaría propiamente dicha no superaba las diez libras ${ }^{82}$. En la décima de 1397, además, se documentan cuatro capellanías en dicha parroquia con un valor total de 23 libras $^{83}$. Por su parte, en la décima de 1456 su número aumentó hasta las doce con una tasación de 191 libras $^{84}$. Tal como se muestra en la tabla, algo similar ocurría con los vicarios de las parroquias de San Pablo, San Felipe o San Gil quienes duplicaron o, incluso, triplicaron sus rentas. En estos casos, además, se documenta un amplio número de capellanías que en las anteriores colectas no aparecen registradas ${ }^{85}$.

Pese a este aumento generalizado de las tasas de los vicarios y rectores parroquiales, también constatamos que menguaron las rentas de otros centros. Una de las reducciones más drásticas la encontramos en las rentas de la parroquia de San Antón de Vienne. En 1355 y 1397 el comendador estaba tasado con 31 libras, mientras que en la colecta de 1456 menguó hasta las 16 libras ${ }^{86}$. Algo similar sucedió con el vicario de San Jaime, que redujo su riqueza en cinco libras con respecto a la colecta de $1397^{87}$, o con el vicario de Santa María de Altabás. En particular, esta vicaría parroquial estaba tasada, en las décimas de 1355 y de 1397, con 17 libras, si bien en la décima de 1456 su cantidad se situó en torno a siete libras ${ }^{88}$.

81 ACA, RP, décimas, reg. 1935, f. 25v.

${ }^{82}$ En particular, en la décima de 1397 el vicario estaba tasado con nueve libras (ACA, RP, décimas, reg. 1901, f. 17v) y el coadjutor del vicario con 5 libras (ACA, RP, décimas, reg. 1901, 18r).

83 ACA, RP, décimas, 1901, ff. 18r-v.

84 ACA, RP, décimas, 1935, ff. 25v-27r. Muchas de las capellanías tasadas con más de 15 libras no se habían documentado en la décima de 1397.

${ }^{85}$ La parroquia de San Gil, por ejemplo, contaba con una importante presencia de ciudadanos honrados que tenían un peso destacado en el gobierno urbano: MAINÉ, 2006: 122-123. Por lo que aquí nos interesa, a mitad del siglo XV, en la parroquia de San Gil se documentan trece capellanías con una valoración conjunta de 186 libras y tan solo la capellanía instituida por Miguel de Capiella tenía una renta de 25 libras anuales.

${ }^{86}$ ACA, RP, décimas, reg. 1801, f. 2r; reg. 1901, f. 15r. ACA, RP, décimas, reg. 1935, f. 45r. La realidad de la parroquia de San Antón y el resto de las rentas instituidas resulta más complicado de rastrear por la influencia que tenía sobre ella la misma colegiata de Santa María: LOZANO, 2016: 502.

${ }^{87}$ De hecho, en la décima de 1456 estuvo exento de pago: ACA, RP, décimas, reg. 1901, f. 23 r.

88 ACA, RP, décimas, reg. 1801, f. 2v; reg. 1901, f. 28v; reg. 1935, f. 37v. 


\section{CONSIDERACiOnes Finales}

Una vez analizados los principales datos que ofrecen los libros de tasas decimales para la ciudad de Zaragoza, pueden hacerse una serie de consideraciones finales que, sin duda, tendrán que ser corroboradas y constituir los ejes de futuras investigaciones en curso.

En primer lugar, no cabe duda de que los libros de tasas beneficiales son un reflejo del estado y la disposición de la Iglesia bajomedieval. Hasta un periodo reciente, muchos autores coincidían a la hora de señalar la importancia de estas fuentes para el análisis de la geografía eclesiástica o la toponimia, pero dejaban de lado su potencial como fuente fiscal ${ }^{89}$. Gracias a la proliferación, durante los últimos años, de nuevas líneas de investigación dedicadas a esta cuestión, se puede comprobar cómo el estudio seriado de los libros de tasas eclesiásticas también aporta información muy relevante sobre la composición socioeconómica del clero bajomedieval y su capacidad contributiva. Como ya se ha apuntado, durante las décadas centrales del siglo XIV se inicia un periodo de intensa presión fiscal sobre el clero en la Corona de Aragón en el que se sucedieron, casi sin solución de continuidad, la recaudación de las décimas en paralelo a los donativos otorgados por el brazo eclesiástico en Cortes y subsidios particulares $^{90}$. En este contexto, y teniendo en cuenta los ajustes que se produjeron en la valoración decimal desde comienzos del siglo XV y, sobre todo, con las averiguaciones de mediados del siglo $\mathrm{XV}$, los distintos grupos que componían el clero se convirtieron en sujetos fiscales activos y su contribución permite establecer de forma harto precisa cómo se distribuyó la riqueza dentro de este importante colectivo.

Así, en el caso de las dignidades eclesiásticas del obispado zaragozano, cabe poner de relieve, en primer lugar, que la sistematización de los datos fiscales disponibles permite disponer de información de gran interés sobre cada beneficio eclesiástico y su titular. Más allá de la pertenencia a una iglesia o monasterio y su tasación decimal, en muchas ocasiones documentamos el nombre del beneficiado y su cargo (canónigo, rector, vicario, cantor). De este modo, es posible conocer no solo la situación económica de las principales dignidades de la diócesis, sino también la jerarquía eclesiástica, el ascenso en los cargos y las relaciones de poder tanto con la monarquía como con el papado. Asimismo, un estudio detallado de estos datos permite establecer qué dignidades estaban exentas de pago, la razón por la que no contribuían y, lo más interesante, la evolución que sufrieron sus rentas a lo largo del tiempo. Como puede suponerse, los eclesiásticos que más aumentaron su contribución fueron aquellos que

\footnotetext{
${ }^{89}$ Remito de nuevo a los estudios de J. M. Latorre, entre otros, para la época moderna, donde ya sugiere esta cuestión: LATORRE, 2009: 57-94.

90 TELLO, 2020: 283. LAFUENTE, 2017: 113-146. SÁNCHEZ, 2011: 133-165; 2005: 363-393.
} 
lograron disponer de un mayor número de beneficios u ostentar otros privilegios eclesiásticos. Por lo que respecta a los exentos, estos lo eran, bien porque no llegaban al mínimo contributivo, o bien porque disfrutaban de alguna condición privilegiada (cardenales, colectores principales, etc.). Dejando de lado figuras ya analizadas, como la del arzobispo o la de los camareros, conviene poner énfasis en la progresiva acumulación de beneficios o rentas eclesiásticas por parte de algunos miembros del cabildo catedralicio, tal como se observa, por ejemplo, a lo largo del siglo XV. Con todo, debe advertirse también que las rentas que disponía cada dignidad variaron bastante a finales de la Edad Media, seguramente por la propia evolución de la geografía fiscal y por las transferencias de rentas.

En segundo lugar, puede observarse que durante la Baja Edad Media se fueron incorporando a los inventarios de tasas multitud de beneficios simples. Aunque aquí no es posible analizarlos en su conjunto, parece evidente que, con la revalorización de las tasas de mediados del siglo $\mathrm{XV}$, se documentan un gran número de capellanías y beneficios que no aparecen en los libros contables anteriores, si bien ello no siempre significa que no existiesen (o que fuesen en todos los casos de nueva fundación). El estudio de las fundaciones en los dos principales centros de la ciudad, la catedral y Santa María la Mayor, confirma la importancia que adquirió la disposición de capellanías y aniversarios en la sociedad bajomedieval y el especial interés que existió por mantener vivo su culto. Conviene recordar además que, más allá de las instituidas por eclesiásticos, muchos de estos entes fueron erigidos por importantes nobles, caballeros y ciudadanos zaragozanos que desempeñaron importantes funciones en la corte y en el municipio zaragozano; todos ellos, obviamente, tenían un patrimonio lo suficientemente importante como para dotar un beneficio perpetuo. Sin duda, sería necesario ampliar esta información con documentación notarial y municipal que permitiría saber cuándo y cómo se dotaron y a quién se puso al frente. Esto posibilitaría, asimismo, conocer, por un lado, el número de capellanías instituidas por cada uno de estos agentes, y por otro, el papel que desempeñaron estos laicos en las parroquias donde constituyeron sus beneficios.

$\mathrm{Y}$ es que, en tercer lugar, hemos visto cómo, en el caso de Zaragoza, la parroquia no era solo una circunscripción religiosa sino también un centro de referencia en torno al cual se articulaba el gobierno urbano. Dejo para un futuro artículo el estudio comparado de la riqueza entre las distintas parroquias urbanas y rurales, que puede constituir un indicador interesante para conocer el peso socioeconómico de las distintas demarcaciones en el interior de la ciudad y allende de las murallas. Tan solo quiero señalar aquí que la riqueza de los rectores o vicarios de cada parroquia estaba en relación con el número y cuantía de rentas que estaban adscritas, directa o indirectamente, a estas circunscripciones. Tal como también hemos visto, la mayoría de las valoraciones de dichas 
parroquias se mantuvieron fijas durante el trescientos y no fue hasta mediados de siglo XV cuando experimentaron considerables variaciones. En el caso de las parroquias de la ciudad de Zaragona, sin embargo, no siempre puede establecerse un patrón claro en la evolución de las tasas decimales, tal como sí parece suceder con las principales dignidades de la catedral y de Santa María.

Lo que sí puede observarse, en general, es un aumento de la valoración de las tasas decimales en el mundo urbano ${ }^{91}$. En efecto, a falta de un estudio más amplio, si ponemos en relación la información extraída del obispado zaragozano con lo observado en obispados como Barcelona o Mallorca, es posible afirmar que en los núcleos urbanos se recaudó cada vez más en concepto de décimas y subsidios, a la par que redujeron — parece ser — bastante menos sus tasas contributivas si se compara con lo sucedido en los centros seculares rurales. Esto nos podría llevar a pensar en un mayor impacto de las coyunturas críticas que se documentan a fines del medioevo en el mundo rural, así como en un incremento del traspaso de la riqueza de manos laicas a eclesiásticas en el mundo urbano, tal como demostraría la importante multiplicación de beneficios. Todo ello, no obstante, son de momento hipótesis de trabajo que deberán ser confirmadas o desmentidas por futuros estudios.

\section{Bibliografía}

Abulafia, David, The Western Mediterranean Kingdoms. The Struggle for Dominion. 1200-1500, Londres, Routledge/The Medieval World, 1997.

Abulafia, David, «El mediterrani en temps del Magnanim: il mediterráneo a ll'epoca di Alfonso il magnánimo», en Alfons el Magnànim de València a Nàpols. Actes del Congrés del 550 aniversari de la mort d'Alfons el Magnànim 1394-1458, Valencia, Institució Alfons el Magnànim/Diputació de València, 2009: 97-112.

Alfani, Guido y Di Tullio, Matteo, The Lion's Share Inequality and the Rise of the Fiscal State in Preindustrial Europe, Cambridge, Cambridge University Press, 2019.

Álvarez Palenzuela, Vicente Ángel, «Los intereses aragoneses en Italia: presiones de Alfonso V sobre el papado», en La Corona d'Aragona in Italia (secc. XIII-XVIII). XIV Congresso di Storia della Corona d'Aragona (Sassari, 1900), Sassari, C. Delfino, 1993, vol. 3: 65-89.

Aventín i Puig, Merçé, «Mercat de rendes, mercat de salvació», en Manuel Sánchez Martínez (ed.), Estudios sobre renta, fiscalidad y finanzas en la Cataluña bajomedieval, Barcelona, CSIC, 1993: 133-151.

Battelli, Guido, Rationes decimarum italiae nel secoli XIII e XIV, Ciudad del Vaticano, Biblioteca Apostolica Vaticana, 1946.

${ }^{91}$ En las parroquias de la parte foránea y del entorno rural sí se pueden observar cambios o reajustes más generalizados durante estas décadas.

Hispania, 2021, vol. LXXXI, n. ${ }^{\circ}$ 267, enero-abril, págs. 11-43, ISSN: 0018-2141, e-ISSN: 1988-8368

https://doi.org/10.3989/hispania.2021.001 
Baucells i Reig, Josep, «El subsidi eclesiàstic de l'any 1451», en La Corona d'Aragona e il Mediterraneo: aspetti e problema comuni da Alfonso il Magnanimo a Ferdinando il Cattolico (1416-1516). IX Congresso di Storia della Corona d'Aragona (Napoli, 1973), Palermo, Accademia di Scienze Lettere e Arti, 1984, vol. III: 11-33.

Baydal Sala, Vicent, «Tan grans messions. La financiación de la cruzada de Jaime II de Aragón contra Almería en 1309», Medievalismo: Boletín de la Sociedad Española de Estudios Medievales, 19 (Madrid, 2009): 57-154.

Bertran Roigé, Prim, «El poder de l'Església medieval: organització administrativa i sistema fiscal en el segle XIV», L’Avenç, 139 (Barcelona, 1990): 66-69.

Bertran Roigé, Prim, «La clerecia regular dels bisbats catalans, segons la dècima apostòlica de 1391», en El poder real de la Corona de Aragón (siglos XIV-XVI). XV Congreso de Historia de la Corona de Aragón (Jaca, 1993), Zaragoza, Diputación de Educación y Cultura, 1996, t. I, vol. 5: 523-534.

Bertran Roigé, Prim, «La fiscalitat eclesiàstica en els bisbats catalans (1384-1392. Tipologies impositives i diferències territorials», Acta Historica et Archaeologica, 18 (Barcelona, 1997): 281-300.

Bertran Roigé, Prim, «Patronat reial sobre benifets ecclesiàstics a la corona catalanoaragonesa», Analecta Sacra Tarraconensia, 71 (Barcelona, 1998): 131-141.

Blasco, Asunción y San Vicente, Ángel (coords.), Formularios notariales aragoneses. T. II. Formulario notarial de Gil de Borau: Zaragoza, siglo XIV, Zaragoza, El Justicia de Aragón, 2001.

Borau i Morell, Cristina, Els promotors de capelles i retaules a la Barcelona del segle $X I V$, Barcelona, Fundació Noguera, 2003.

Canellas López, Ángel, «Zaragoza Medieval (1162-1479)», en Antonio Beltrán y José M. Lacarra (coords.), Historia de Zaragoza, T. I, Zaragoza, Zaragoza, Ayuntamiento de Zaragoza, 1976: 197-425.

Canellas López, Ángel, Monumenta diplomatica aragonensia: los cartularios de San Salvador de Zaragoza, Zaragoza, Cai-Ibercaja, 1990.

Carocci, Sandro y Collavini, Simone M., «The Costs of States: Politics and Exactions in the Christian West (Sixth to Fifteenth Centuries)», en John Hudson y Ana Rodríguez (eds.), Diverging Paths? The shapes of power and institutions in Medieval Christendom and Islam, Leiden/Boston, Brill, 2014: 125-158.

Casorrán Berges, Esther, Santa María la Mayor de Zaragoza a través de sus documentos (1118-1318). Historia, devoción y tradición, tesis doctoral inédita, Universidad de Zaragoza, 2016.

Cateura, Pau y Tudela, Luis (eds.), La crisi baixmedieval a la Corona d'Aragó (13501450), Palma de Mallorca, ed. Illa, 2019.

Causse, Bernad, Église, finance et royauté: la florasion des décimes dans la France du Moyen Âge, Paris, Aux Amateurs de Livres, 1988, 2 vols.

Cuella Esteban, Ovidio, Bulario aragonés de Benedicto XIII. Tomo I. La Curia de Aviñón (1394-1403), Zaragoza, Institución Fernando el Católico, 2003.

De la Mardière-Chevreau, Christophe y Chevreau, Emmanuelle, «La Dime Saladine», en Ludovic Ayrault y Florent Garnier (coords.), La Revue. La religión et l'impôt. Actes du Colloque de Clermont-Ferrand (2006), Cleremont-Ferrand, Centre Michel de l'Hospital/Université d'Auvergne, 2012: 23-28. 
De la Torre Gonzalo, Sandra, Grandes mercaderes de la Corona de Aragón en la Baja Edad Media. Zaragoza y sus mayores fortunas mercantiles, 1380-1430, Barcelona, CSIC, 2018.

Del Campo Gutiérrez, Ana, El Libro de Testamentos de 1384-1407 del notario Vicente de Rodilla Una introducción a los documentos medievales de últimas voluntades de Zaragoza, Zaragoza, Institución Fernando el Católico, 2011.

Del Campo Gutiérrez, Ana, «Aproximación a un mapa devocional de Zaragoza en el siglo XIV», Turiaso, 16 (Tarazona, 2001-2002): 87-144.

Domingo, Tomás y Gutiérrez, María Rosa, «La gracia del Quinto Diezmero concedida en el año 1409 a la fábrica de La Seo por Benedicto XIII y su primera ejecución en 1412», Aragón en la Edad Media, 14-15 (Zaragoza, 1999): 413-450.

Epstein, Stephan R., Freedom and Growth, Markets and states in Europe, 1300-1750, London, Routledge, 2000.

Eubel, Konrad, Hierarchia catholica medii aevi sive Summorum Pontificum, S.R.E. Cardinalium, Ecclesiarum antistitum ab anno 1198 usque ad annum 1431 perducta, Padova, Il messaggero di S. Antonio, 1968 [primera edición: 1913].

Fàbrega i Grau, Ángel, «La dècima per a la conquesta de Sardenya en els pontificats de Bonifaci VIII i Benet XI», en Relaciones Económicas y Comerciales en el Mediterráneo del Siglo XII al Siglo XVI. VI Congreso de Historia de la Corona de Aragón (Cerdeña, 1957), Madrid, Dirección General de Relaciones Culturales, 1959: 461-475.

Fàbrega i Grau, Ángel, «La ayuda económica de la Iglesia a Jaime II de Aragón para la conquista de Cerdeña», Anthologica Annua, 11 (Roma, 1963): 11-46.

Farelo, Mario, «Payer au roi et au pape. Les décimes pontificales imposées au clergue portugais pendant l'époque avignonnaise», en Jordi Morelló Baget (ed.), Financiar el reino terrenal. La contribución de la Iglesia a finales de la Edad Media (siglos XIII-XVI), Barcelona, CSIC, 2013: 55-106.

Favier, Jean, «Temporels ecclésiastiques et taxation fiscale: le poids de la fiscalité pontificale au XIVe siécle», Journal des savants, 2 (París, 1964): 102-127.

Favier, Jean, Les finances pontificales à l'époque du grand schisme d'Occident (13781409), Roma/París, École française d'Athenes et de Rome, 1966.

Favier, Jean, «Finances pontificales (XIIIe-XVe)», en Philippe Levillain (coord.), Dictionnaire Historique de la Papauté, Paris, Fayard, 2006: 683-687.

Fortea Pérez, José Ignacio, «La Hacienda de los Estados Pontificios en los inicios de la Modernidad (1420-1565)», en Estados y mercados financieros en el Occidente cristiano (siglos XIII-XVI). Actas de la XLI Semana de Estudios Medievales de Estella (Estella, 2014), Pamplona, Gobierno de Navarra, 2015: 473-508.

Furió Diego, Antoni, «La Crisis de la Baja Edad Media: una revisión», en Antoni Furió Diego (coord.), Las crisis a lo largo de la Historia, Valladolid, Universidad de Valladolid, 2010: 15-45.

García Ciprés, Gregorio, «Ricos hombres de Aragón: los Bardaxí», Linajes de Aragón, 3 (Zaragoza, 1912): 5-9

Giménez Soler, Andrés, «El Justicia de Aragón Juan Giménez Cerdán», Revista de Archivos, Bibliotecas y Museos, 1 (Madrid, 1897): 337-346. 
González Antón, Luis, «La vinculación familiar del cargo de Justicia y sus consecuencias institucionales», en Tercer Encuentro de Estudios sobre el Justicia de Aragón (Zaragoza, 2002), Zaragoza, El Justicia de Aragón, 2002: 9-31.

Goñi Gaztambide, José, «Una bula de Juan XXII sobre la división de la provincia de Tarragona (24 abril 1318)», Hispania Sacra, 7 (Madrid, 1954): 87-92.

Goñi Gaztambide, José, Historia de la bula de la cruzada en España, Vitoria, Editorial del Seminario, 1958.

Gutiérrez Iglesias, María Rosa, «La Mensa capitular de la iglesia de San Salvador de Zaragoza en el pontificado de Hugo Mataplana», Cuadernos de Historia Jerónimo Zurita, 35-36 (Zaragoza, 1980): 7-116.

Hinojosa Montalvo, José, Jaime II y el esplendor de la Corona de Aragón, San Sebastián, Nerea, 2005.

Ivars, Andrés, La «indiferencia» de Pedro IV de Aragón en el gran cisma de occidente, Madrid, Asilo de huérfanos del S. C. de Jesús, 1928.

Kern, Hanspeter, «La peste negra y su influjo en la provisión de los beneficios escolásticos», en La corona de Aragon en el siglo XIV. VIII Congreso de Historia de la Corona de Aragón (Valencia, 1967), Valencia, s. e., 1973, vol. I: 71-84.

Küchler, Winfried, Les finances de la Corona d'Aragó al segle XV (regnats d'Alfons $V$ i Joan II), Valencia, Generalitat de València, 1996.

Ladero Quesada, Miguel Ángel, «Renta eclesiástica en la Castilla del siglo XV», en El siglo XV en Castilla. Fuentes de renta y política fiscal, Barcelona, Ariel, 1982: 190-212.

Ladero Quesada, Miguel Ángel, Fiscalidad y poder real en Castilla (1252-1369), Madrid, Real Academia de la Historia, 1993.

Ladero Quesada, Miguel Ángel, «Lo antiguo y lo nuevo de la investigación sobre fiscalidad y poder político en la Baja Edad Media hispánica», en Estados y mercados financieros en el Occidente cristiano (siglos XIII-XVI). Actas de la XLI Semana de Estudios Medievales de Estella (Estella, 2014), Pamplona, Gobierno de Navarra, 2014: 13-55.

Lafuente Gómez, Mario, «La fiscalidad extraordinaria en la financiación de las guerras de Cerdeña por la Corona de Aragón (1320-1410)», en Olivetta Schena y Sergio Tognetti (coords.), Commercio, finanza e guerra nella Sardegna tardomedievale, Roma, Viella, 2017: 113-146.

Lafuente Gómez, Mario y Martínez, Sergio, «Ejército y fiscalidad en la encomienda santiaguista de Montalbán (Aragón) durante la guerra de los dos Pedros (13561366)», Espacio, Tiempo y Forma. Serie III. Historia Medieval, 24 (Madrid, 2011): 109-142.

Laliena Corbera, Carlos, «Dinámicas de crisis. La sociedad rural aragonesa al fino de 1300», en José Ángel Sesma Muñoz (coord.), La Corona de Aragón en el centro de su historia, 1208-1458: aspectos económicos y sociales, Zaragoza, Gobierno de Aragón/Grupo CEMA, 2011: 61-88.

Latorre Ciria, José Manuel, «Las propiedades del Cabildo de la Catedral de Huesca (siglo XVI)», en Jeronimo Zurita, su época y su escuela. Congreso Nacional de Jerónimo Zurita (Zaragoza, 1983), Zaragoza, Institución Fernando el Católico, 1986: 275-282. 
Latorre Ciria, José Manuel, «Los señoríos del arzobispo de Zaragoza en la Edad Moderna: Población y estructura de las rentas», en Gregorio Colás Latorre (ed.), Estudios sobre el Aragón foral, Zaragoza, Mira, 2009: 57-94.

Le Roux, Amandine, «Le Recouvrement de la décime par les collecteurs pontificaux de 1316 à 1503 (royaume de France et Provence)», en Daniel Baloup y Manuel Sánchez (coords.), Partir en croisade à la fin du Moyen Âge. Financement et logistique, Toulouse, Presses universitaires du Midi, 2015: 55-79.

Levillain, Philippe (coord.), Dictionnaire Historique de la Papauté, París, Fayard, 2006.

Lozano Gracia, Susana, «La población de la ciudad de Zaragoza en los siglos XIV y $\mathrm{XV} »$, en José Ángel Sesma y Carlos Laliena (coords.), La población de Aragón en la Edad Media (siglos XIII-XV), Zaragoza, Grupo CEMA, 2004: 471-518.

Lozano Gracia, Susana, "Las parroquias y el Poder Urbano en Zaragoza durante los siglos XIV y XV», En la España Medieval, 29 (Madrid, 2006): 135-151.

Lozano Gracia, Susana, Las elites en la ciudad de Zaragoza a mediados del siglo XV: La aplicación del método prosopográfico en el estudio de la sociedad, tesis doctoral inédita, Universidad de Zaragoza, 2012.

Lunt, William E., Papal Revenues in the Middle Ages, Nueva York, Columbia University Press, 1935 [reimp. 1965].

Mainé Burguete, Enrique, Ciudadanos honrados de Zaragoza. La oligarquía zaragozana en la Baja Edad Media (1370-1410), Zaragoza, Grupo CEMA, 2006.

Miguel, Isidoro, Andrés, Jorge y Casorrán, Esther, «En la estela del Cisma de Occidente. Dos nuevas bulas del Papa Luna en los Archivos Capitulares de Zaragoza», Aragón en la Edad Media, 20 (Zaragoza, 2008): 479-503.

Mollat, Guillem (ed.), Lettres communes de Jean XXII (1316-1334). Collection des Registres et lettres des papes du XIVe siècle [LCJXXII], Roma/Atenas, École française d'Athenes et de Rome, 1921.

Montagut i Estragués, Tomàs, El Mestre Racional a la Corona d'Aragó (1283-1419), Barcelona, Fundació Noguera, 1987.

Montes Romero-Camacho, Isabel, «Poder real y fiscalidad eclesiástica en los orígenes del estado moderno. La contribución de la Iglesia sevillana a la Hacienda Real de Castilla en tiempos de los primeros Trastámara (1369-1420)», en Castilla y el mundo feudal. Homenaje al profesor Julio Valdeón, vol. II, Valladolid, Junta de Castilla y León/Universidad de Valladolid, 2009: 649-664.

Morelló Baget, Jordi, «La contribución de la Iglesia a las arcas del rey: a propósito de la recaudación de las décimas en la Corona de Aragón a finales del siglo XIV y principios del XV», en Denis Menjot y Manuel Sánchez (eds.), El dinero de Dios. Iglesia y fiscalidad en el Occidente Medieval (siglos XIII-XV), Madrid, Instituto de Estudios Fiscales, 2011a: 167-190.

Morelló Baget, Jordi, «Las relaciones monarquía-papado en la etapa final del Gran Cisma y la sucesión de dos modelos distintos de transferencia fiscal en la Corona de Aragón», en José Ángel Sesma Muñoz (coord.), La Corona de Aragón en el centro de su historia, 1208-1458: aspectos económicos y sociales, Zaragoza, Gobierno de Aragón/Grupo CEMA, 2011b: 233-263.

Hispania, 2021, vol. LXXXI, n. ${ }^{\circ}$ 267, enero-abril, págs. 11-43, ISSN: 0018-2141, e-ISSN: 1988-8368 
Morelló Baget, Jordi, «Acerca de la contabilización de los veros valores en la Corona de Aragón y la gestión del subsidio eclesiástico de 1443 (a partir de las cuentas de un notario barcelonés)», en Thierry Pecourt (dir.), De l'autel à l'écritoire. Aux origines des comptabiités princières en Occident (XII-XIV siècle). Actes du colloque internationa d'Aix-en-Provence (Aix en Provence 2013), París, Boccard, 2015: 289-322.

Morelló Baget, Jordi, «En torno a la disyuntiva décima/subsidio en Castilla y la Corona de Aragón durante la Baja Edad Media», Hispania, 257 (Madrid, 2017): 643-671.

Morelló Baget, Jordi, «La contribució de l'Església en el context de la crisi baixmedieval: anàlisi diacrònica de la fiscalitat beneficial al bisbat de Barcelona», en Pere Orti y Pere Verdés (eds.), Barcelona en crisi? La Ciutat al segle XV, Barcelona, Museu d'Història de Barcelona (en prensa).

Morerod, Jean Daniel, «Taxation décimale et frontières politiques en France aux XIII et XIV siécles», en Aux origines de l'État Moderne. Le fonctionnement administratif de la papauté d'Avignon. Actes de la table ronde organisée par l'École française du CNRS (Avignon, 23-24 janvier 1988), Roma/París, École française de Rome, 1990: 329-350.

Navarro Espinach, Germán, «La formación de los señoríos del condado de Aranda», en María Jesús Casaus Ballester (coord.), El Condado de Aranda y la nobleza española en el Antiguo Régimen, Zaragoza, Institución Fernando el Católico, 2009: 65-84.

Navarro Sorni, Miguel, Alfonso de Borja, Papa Calixto III. En la perspectiva de sus relaciones con Alfonso el Magnánimo, Valencia, Institució Alfons el Magnànim/ Diputació de València, 2003.

Navarro Sorni, Miguel, «Alfonso el magnánimo y la iglesia: Calixto III Borja», en Alfons el Magnànim de València a Nàpols. Actes del Congrés del 550 aniversari de la mort d'Alfons el Magnànim 1394-1458, Valencia, Institució Alfons el Magnànim/Diputació de València, 2009: 247-260.

Nieto Soria, José Manuel, Iglesia y génesis del Estado Moderno en Castilla (13691480), Madrid, ed. Complutense, 1994.

Ortego Rico, Pablo, «Las riquezas de la Iglesia al servicio del poder monárquico: los empréstitos eclesiásticos en la Castilla del siglo XV», En la España Medieval, 35 (Madrid, 2012): 145-176.

Péquignot, Sthepane, Au nom du roi. Pratique diplomatique et pouvoir durant le règne de Jacques II d'Aragon (1291-1327), Madrid, Casa de Velázquez, 2009.

Perrone, Sean, Charles $V$ and the Castilian Assembly of the Clergy: Negotiations for the Ecclesiastical Subsidy, Leiden/Boston, Brill, 2008.

Pezzolo, Luciano, «Tassare e pagare le tasse tra medioevo e prima età moderna», en Claudio Azzara, Ermanno Orlando, Marco Pozza y Alessandra Rizzi (eds.), Historiae. Scritti per Gherardo Ortalli, Venecia, ed. Ça'Foscari, 2013: 237-251.

Piketty, Tomas, L'économie des inégalités, París, La Découverte, 2008.

Pueyo Colomina, Pilar, «La Peste Negra en la diócesis de Zaragoza: el registro de actos comunes del arzobispo Guillermo de Agrifolio (1348-1350)», Aragón en la Edad Media, 10-11 (Zaragoza, 2013): 705-735. 
Rius Serra, Josep, Rationes decimarum Hispaniae (1279-80), Barcelona, CSIC, 1946, 2 vols.

Rodrigo Esteban, María Luz, Documentos para la historia del Justicia de Aragón, vol. I Archivo Histórico de la Corona de Aragón, Zaragoza, El Justicia de Aragón, 1991.

Rodríguez López, Ana, «Modelos de diversidad: crecimiento económico y crisis en los reinos hispanos en la Baja Edad Media», Vínculos de Historia, 2 (Castilla-La Mancha, 2013): 27-49.

Ronzani, Mauro, «Come lavorare con le rationes decimarum? Riflessioni sul rapporto fra l'insediamento e le forme d'inquadramento civile ed ecclesiastico in Toscana fra due e trecento», en Paola Galetti (ed.), Paesaggi, comunità, villaggi medievali. Atti del Convegno internazionale di studio (Bologna, 2010), Spoleto, Centro Italiao di Studi sull'Alto Medioevo, 2012: 525-534.

Ruiz de Loizaga, Saturnino, «La peste negra en la Península Ibérica: alusiones, evocaciones, recurrencias (siglo XV). Según documentación del Archivo Vaticano», Scriptorium Victoriense, 57 (Vitoria, 2010): 403-423.

Ryder, Alan, Alfonso the Magnanimous. King of Aragon, Naples, and Sicily 13961458, Oxford, Oxford University Press, 1987.

Sabaté, Flocel (ed.), The Crown of Aragon: a singular Mediterranean Empire, Leiden, Brill, 2017.

Salas Almela, Luis (ed.), Los ámbitos de la fiscalidad: fronteras, territorio y percepción de tributos en los imperios ibéricos (siglos XV-XVIII), Madrid, Ministerio de Economía y Hacienda/Instituto de Estudios Fiscales, 2011.

Sánchez, Manuel, Furió, Antoni y Sesma, J. Ángel: «Old and New Forms of Taxation in the Crown of Aragon (13th-14th Centuries)», en Simonetta Cavaciocchi (ed.), La fiscalità nell'economia europea secc. XIII-XVIII, Atti della «Trentanovesima Settimana di Studi», (Prato, 2007), Florencia, Firenze University Press, 2008, vol. I: 99-130.

Sánchez Martínez, Manuel, «Fiscalidad pontificia y finanzas reales en Cataluña a mediados del siglo XIV: las décimas de 1349, 1351 y 1354», Estudis Castellonencs, 66 (Castellón, 1994-1995): 1.277-1.296.

Sánchez Martínez, Manuel, «Las cortes de Cataluña en la financiación de la guerra de Arborea. Segunda mitad del siglo XIV», en Maria Teresa Ferrer, Josefina Mutgé y Manuel Sánchez (eds.), La Corona Catalanoaragonesa i el seu entorn mediterrani a la baixa Edat Mitjana, Barcelona, CSIC, 2005: 363-393.

Sánchez Martínez, Manuel, «La participación de la Iglesia de Cataluña en las finanzas regias: los subsidios extraordinarios (1249-1400)», en Denis Menjot y Manuel Sánchez Martínez (eds.), El dinero de Dios. Iglesia y fiscalidad en el Occidente Medieval (siglos XIII-XV), Madrid, Instituto de Estudios Fiscales, 2011: 133-165.

Serrano Montalvo, Antonio, La población de Aragón según el fogaje de 1495, Zaragoza, Institución Fernando el Católico, 1997.

Sesma Muñoz, José Ángel, «La nobleza bajomedieval y la formación del estado moderno en la corona de Aragón», en La nobleza peninsular en la Edad Media, Ávila, Fundación Sánchez Albornoz, 1999: 343-430. 
Sodani, Maria Elisa, «Alfonso il Magnanimo in Italia: pacificatore o crudel tiranno? Dinamiche politico-economiche e organizzazione del consenso nella prima fase della guerra con Firenze (1447-1448)», Archivio storico italiano, 165 (Florencia, 2007): 266-324.

Soria Mesa, Enrique, «Las capellanías en la Castilla Moderna: familia y ascenso social», en Antonio Irigoyen y Antonio Pérez (eds.), Familia, transmisión y perpetuación (siglos XVI-XIX), Murcia, Universidad de Murcia, 2002: 135-148.

Stiglitz, Joseph E., The Price of Inequality: How Today's Divided Society Endangers, Our Future, Nueva York, Norton \& Co, 2012.

Stump, Philipe H., «The Reform of Papal Taxation at the Council of Constance (14141418)», Speculum, 64 (Alicante, 1989): 69-105.

Stump, Philip H., "The council of Constance (1414-1418) and the end of the Schism», en Joëlle Rollo-Koster y Thomas M. Izbicku (eds.), A Companion to the Great Western Schism, Leiden/Boston, Brill, 2009: 395-443.

Tello Hernández, Esther, «La comptabilité des décimes pontificales dans la Couronne d'Aragon (1309-1456)», Comptabilités [en ligne], 10 (2019a), URL: http://journals.openedition.org/comptabilites/2491

Tello Hernández, Esther, «La evolución de las tasas beneficiales en el obispado de Mallorca (1375-1456), ¿un indicador de crisis?», en Pau Cateura y Luis Tudela (eds.), La crisi baixmedieval a la Corona d'Aragó (1350-1450), Palma de Mallorca, ed. Illa, 2019b: 103-120.

Tello Hernández, Esther, Pro defensione regni: Corona, Iglesia y fiscalidad durante el reinado de Pedro IV de Aragón (1349-1387), Madrid, CSIC, 2020.

Trenchs i Òdena, Josep, «La diócesis de Zaragoza y la peste de 1348», Cuadernos de Historia Jerónimo Zurita, 25-26 (Zaragoza, 1962): 119-139.

Triano Milán, José Manuel, La llamada del rey y el auxilio del reino. Del pedido a las contribuciones de la Santa Hermandad (1406-1498), Sevilla, Editorial Universidad de Sevilla, 2018.

Villarroel González, Óscar, El rey y la Iglesia castellana. Relaciones de poder con Juan II (1406-1454), Madrid, Fundación Areces, 2011.

Villarroel González, Oscar, «La tributación de los eclesiásticos castellanos en el siglo XV: entre el rey y el papa», en Jordi Morelló Baget (ed.), Financiar el reino terrenal. La contribución de la Iglesia a finales de la Edad Media (siglos XIII-XVI), Barcelona, CSIC, 2013: 315-343. 